\title{
A Transient Dynamic Model of Brake Corner and Subsystems for Brake Creep Groan Analysis
}

\author{
Dejian Meng, Lijun Zhang, Jie Xu, and Zhuoping Yu \\ School of Automotive Studies, Tongji University, Shanghai 201804, China \\ Correspondence should be addressed to Lijun Zhang; tjedu_zhanglijun@tongji.edu.cn
}

Received 10 July 2017; Accepted 16 October 2017; Published 14 November 2017

Academic Editor: Giorgio Dalpiaz

Copyright (C) 2017 Dejian Meng et al. This is an open access article distributed under the Creative Commons Attribution License, which permits unrestricted use, distribution, and reproduction in any medium, provided the original work is properly cited.

\begin{abstract}
To improve the understanding of brake creep groan, both experimental and numerical studies are conducted in this paper. Based on a vehicle road test under the condition of downhill, complicated stick-slip type motion of caliper and its correlation with the interior noise were analyzed. In order to duplicate these brake creep groan phenomena, a transient dynamic model including brake corner and subsystems was established using finite element method. In the model, brake components were considered to be flexible body, and the subsystems including driveline, suspension, tire, and vehicle body were considered to be rigid body. Simulation and experimental results of caliper vibration in time and frequency domains were compared. It was demonstrated that the new model is effective for the prediction and analysis of brake creep groan, and it has higher accuracy compared to the previous model without the subsystems. It is also found that the lining and caliper not only have stick-slip motion in each coordinate direction but also have translational and torsional movements in plane, which relate to the microscopic sticking and slipping, friction coefficient, and forces, as well as the contact status at the friction interface.
\end{abstract}

\section{Introduction}

In recent years, brake noise, vibration, and harshness (NVH) has become one of the most important issues for the rating of vehicle. Creep groan is one of the brake NVH problems with frequency range usually from 20 to $500 \mathrm{~Hz}$, and it always occurs at low wheel speed and low brake pressure $[1,2]$. Due to the wide use of vehicles equipped with automatic transmission and the increasing of traffic congestion in cities, the incidence and user complaints of brake creep groan increase dramatically. As such, much attention has been paid to this problem in the automotive industry.

Creep groan is generally caused by the stick-slip motion between disc and pads and it is a self-excited vibration of the brake assembly. The phase diagram of the caliper vibration with limit cycle was considered as the experimental evidence of the stick-slip mechanism of creep groan [3]. The gap of static and dynamic friction coefficient was verified to contribute to the propensity of creep groan [4]. The stickslip index obtained in tribotests was demonstrated to have a good correlation with the brake creep groan in vehicle tests [5]. Meanwhile, many theoretical models have been proposed to explain creep groan. Friction oscillator models with single DOF $[6,7]$ and two DOFs $[8,9]$ have been established, and the caliper vibration acceleration in time domain and the bifurcation behavior in phase plane have been used to evaluate creep groan. In these research studies, the contact between pads and disc is assumed to be singlepoint contact, which is different from the real contact in disc brakes. Besides, the components of suspension and driveline system are neglected, which actually have effects on the characteristics of brake creep groan.

Brake creep groan has been proven to be a structureborne vibration [10], which is related not only to brake assembly but also to some subsystems. Considering the components of brake and driveline, and even tire and vehicle mass, a three DOFs translational model [11], a two DOFs torsional model [12], and a four DOFs torsional model [13, 14] were proposed. By taking into account the front and rear suspensions [15], a five DOFs lumped-parameters model was built. But the geometry and structure of most components and their complex spatial movements are neglected in these models, which may reduce the accuracy of the brake creep groan prediction. Therefore, it is necessary to establish more 
comprehensive object-oriented dynamic models. A multibody dynamic model of chassis corner was established using MSC ADAMS [16], and the simulated primary frequency of the caliper acceleration agreed with the test result. Uchiyama and Shishido [17] proposed a FE model of brake corner, which offered valuable reference for brake creep groan analysis. Compared with multibody dynamics method, FE model has significant advantage in the calculation of the interface contact and has higher accuracy than multibody dynamics method. However, in the previous FE models of creep groan, some subsystems such as suspension and driveline components were neglected. The spatial motions of pads and caliper and the microscopic process at the friction surfaces, as well as their relationships with the macroscopic dynamics of creep groan, have been poorly understood.

In this study, a vehicle road test of creep groan under the condition of downhill is conducted. The complicated stickslip type motion of caliper and its correlation with the interior noise are analyzed. In order to analytically and numerically reproduce these phenomena and fill the void in literatures, we propose an object-oriented transient dynamic model of brake corner and subsystems using FE model. In the model, brake components are considered to be flexible body; the subsystems including driveline, suspension, tire, and vehicle body are considered to be rigid body. Key parameters of the model are defined, especially the friction coefficient. Macroscopic and microcosmic stick-slip motion and the spatial motion of lining and caliper, as well as the vibration characteristics of caliper, are analyzed and discussed.

\section{A Vehicle Road Test of Creep Groan under the Condition of Downhill}

When creep groan occurs, the driving force does not necessarily come from engine. It could come from downhill force. The engine can induce the vibration of suspension and the frequency components of the driving force from engine are complicated, which could aggravate the complicacy of creep groan motion. In order to reduce the complicated effect of engine, a vehicle road test of creep groan was conducted under the condition of downhill.

2.1. Test Setup. Equipped with six-speed automatic transmission, a McPherson suspension in front, and a torsion beam suspension in rear, an A-class car is tested. The total mass of the vehicle is $1431 \mathrm{~kg}$ including 2 passengers in front seats. Two triaxial accelerometers are mounted at the piston side of caliper and suspension strut, and the $X, Y$, and $Z$ directions of the accelerometer on the caliper are aligned to the tangential, radial, and axial directions of the disc, respectively. An oil pressure sensor connecting brake tube and hose is used to measure brake pressure. Meanwhile, a microphone is installed near the left ear of the driver to measure the interior noise. These sensors are arranged in the front left chassis corner of the car, as shown in Figure 1.

In the test, the vehicle is put on a ramp road with a slop of $10 \%$. The driver presses the brake pedal and starts the engine and then releases the handbrake and hangs in gear of $\mathrm{N}$ and finally releases brake pedal slowly until the vehicle starts to move. When creep groan occurs, the brake pressure is maintained to keep creep groan occurring as long as possible.

2.2. Test Results. The recorded vibration of caliper can be used to explain the mechanism of creep groan [1-3] and it has a good correlation with the subjective rating of creep groan. The vibration of caliper measured in the test is analyzed as follows. Figure 2 shows a typical vibration of caliper and oil pressure while creep groan is occurring. Figure 2(a) shows two types of stick-slip motion. Type I is a quasiharmonic vibration, which always occurs at the stage of oil pressure maintaining and is marked in rectangular frame. Type II is unsteady vibration impulse sequences with different intervals and intensities, which always occurs at the stage of oil pressure changing. The oil pressure saltation is earlier than the vibration of type II. Because the acceleration in $X$ direction is larger than that in the rest of directions, it was processed using Short-Time Fourier Transform, as shown in Figure 2(b). It exhibits that the vibration of type I has obvious multifrequency components, especially in the time interval of $44 \mathrm{~s}$ to $62 \mathrm{~s}$, but the frequency components of type II are relatively dispersed. Therefore, the vibration of type I from $44 \mathrm{~s}$ to $62 \mathrm{~s}$ is further analyzed.

Figure 3 shows the characteristics of vibration type I from $44 \mathrm{~s}$ to $62 \mathrm{~s}$. In this stage, when brake pressure drops to $7.4 \mathrm{bar}$, the first creep groan occurs. When brake pressure increases slowly to 8 bar, the creep groan lasts for about $18 \mathrm{~s}$. According to the characteristics of acceleration in $X$ direction, the whole process can be divided into seven stages, which are named as $A$ to $G$ in Figure 3. Because creep groan vibration mainly occurs in $X$ direction, the acceleration in $X$ direction is analyzed in time-frequency domain. It can be seen that the characteristics of caliper acceleration in both time domain and frequency domain evolve with time complicatedly when creep groan occurs.

The accelerations in stages $\mathrm{A}, \mathrm{C}$, and $\mathrm{E}$ are exhibited to be intermittent and aperiodic shocks, and their phase diagrams do not have a clear limit cycle, as shown in Figure 4(a). The frequency components in these three stages are relatively dispersed, but $90 \mathrm{~Hz}$ and $180 \mathrm{~Hz}$ are the main frequency components. Thus the vibrations in stages $\mathrm{A}, \mathrm{C}$, and $\mathrm{E}$ are similar to the vibration of type II. The vibration in stages $\mathrm{B}$ and $\mathrm{F}$ is exhibited to be periodic harmonic, and the phase diagram has a typical limit cycle of stick-slip motion, as shown in Figure 4(b). The fundamental frequency is $86 \mathrm{~Hz}$ and the first 5-order frequency components are more significant. The acceleration in stage $\mathrm{D}$ is a periodic harmonic, but it contains two types of harmonics in each period. One has large amplitude and short period, and the other one has low amplitude and long period. Thus, its phase diagram has 2 limit cycles, and it shows that the vibration has a two-periodic motion. The fundamental frequency is $40 \mathrm{~Hz}$ and the first 12order frequency components are more significant. In stage $\mathrm{G}$, the vibration gradually disappears, and the limit cycle returns to the equilibrium position in phase diagram.

The A-weighted sound pressure level of interior noise is shown in Figure 5(a). It exhibits that the sound pressure level increases by $20 \mathrm{~dB}(\mathrm{~A})$ at the moment of creep groan 


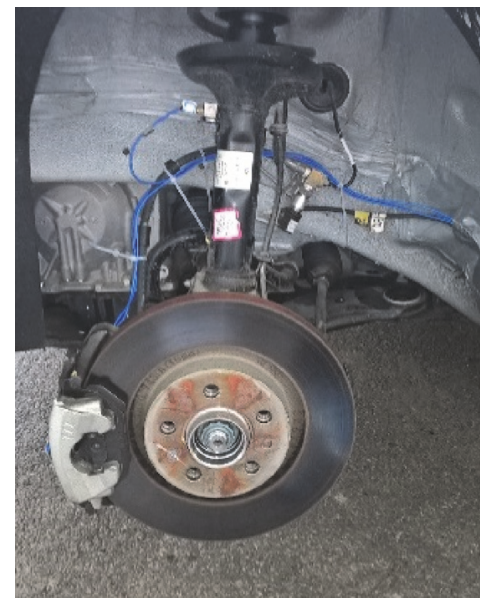

(a)

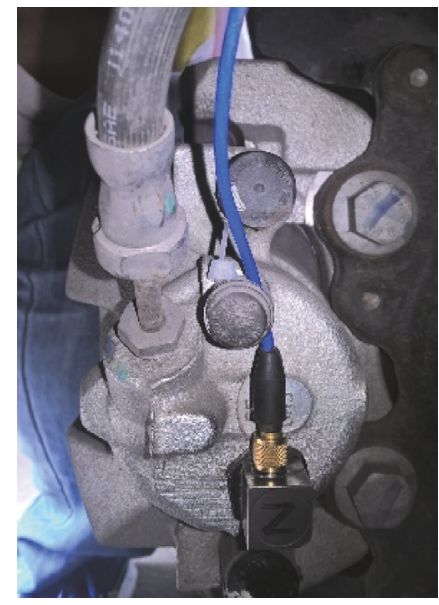

(b)

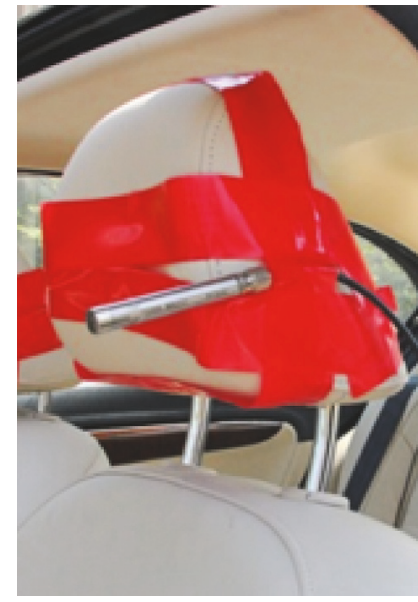

(c)

FIGURE 1: Sensors arrangement in the test of brake creep groan: (a) accelerometers at strut and oil pressure sensor; (b) accelerometers at caliper; (c) microphone.
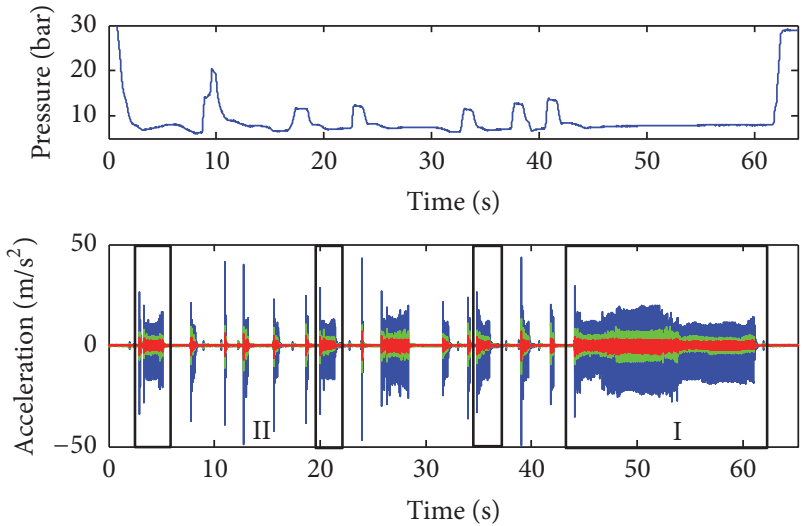

$X$
$-Y$
$-Z$

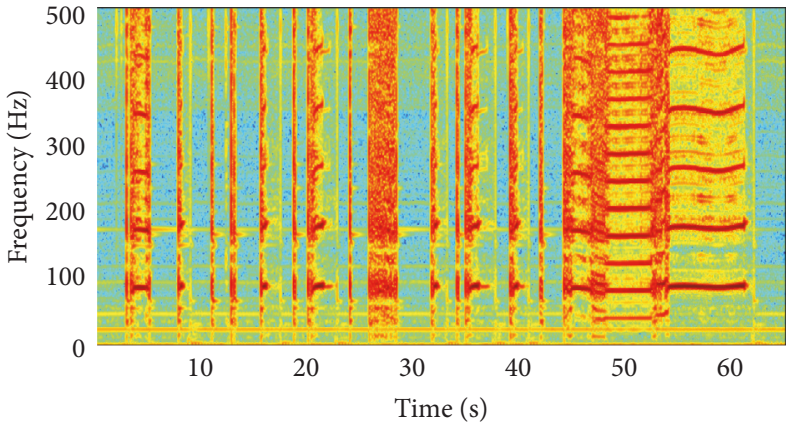

(b)

FIGURE 2: Typical vibrations of caliper in creep groan motion: (a) oil pressure and acceleration of caliper in time domain; (b) time-frequency spectrum of the acceleration in $X$ direction.

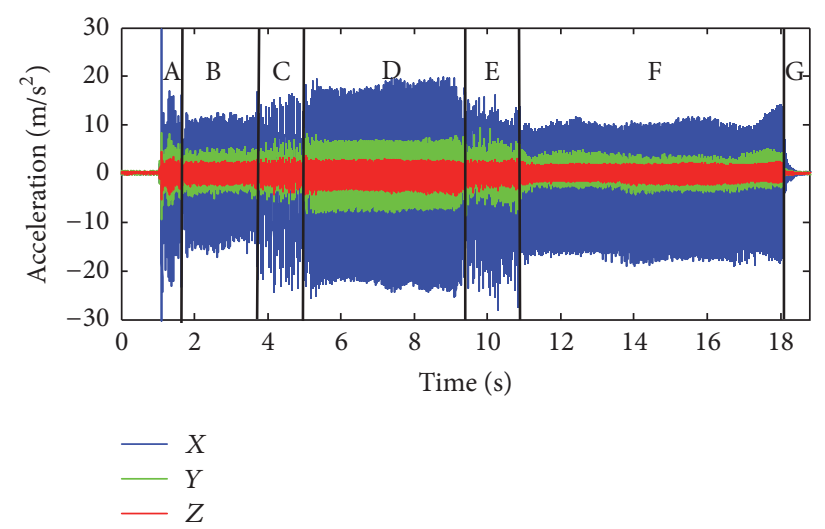

(a)

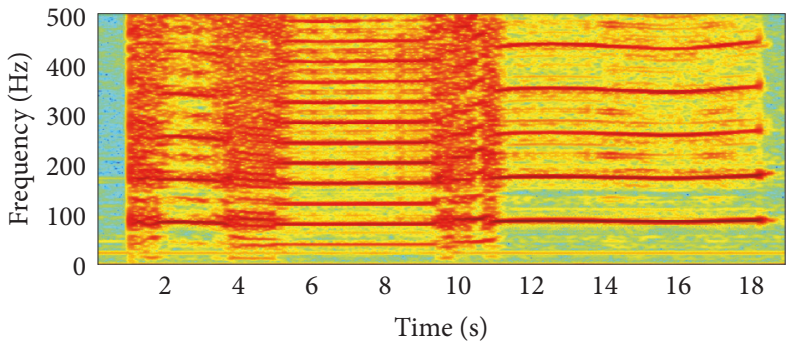

(b)

FIGURE 3: Characteristics of vibration from $44 \mathrm{~s}$ to $62 \mathrm{~s}$ : (a) time history; (b) time-frequency spectrum of acceleration in $X$ direction. 

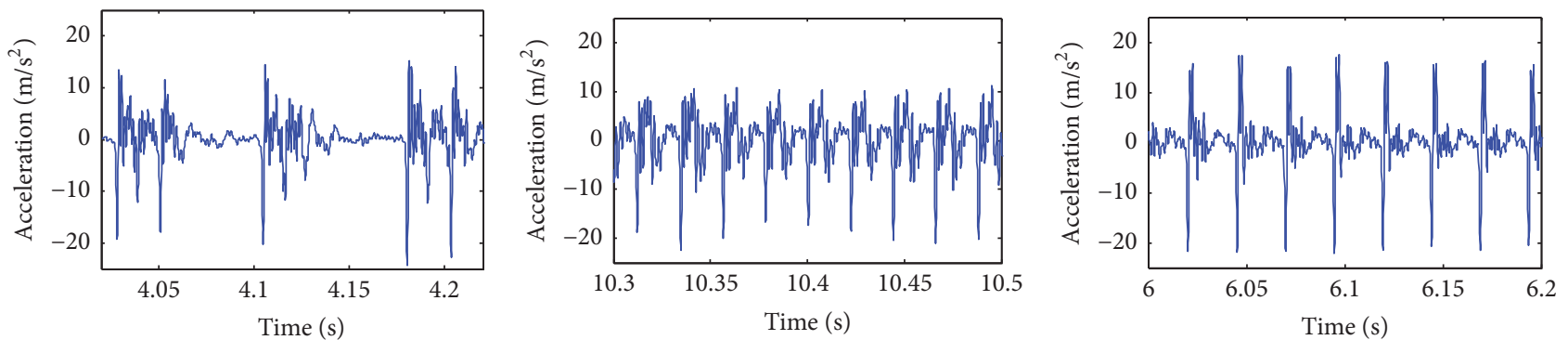

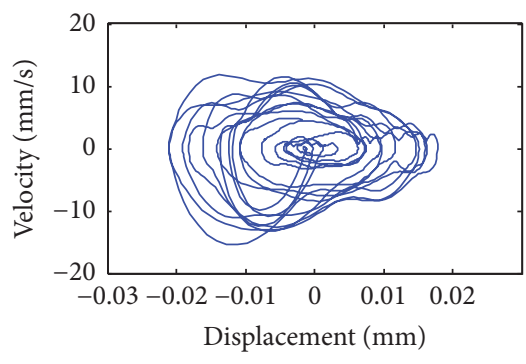

(a)

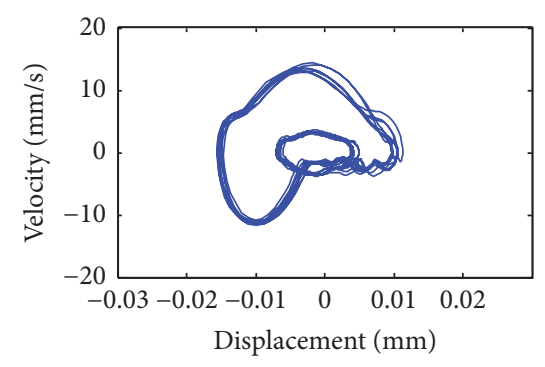

(b)

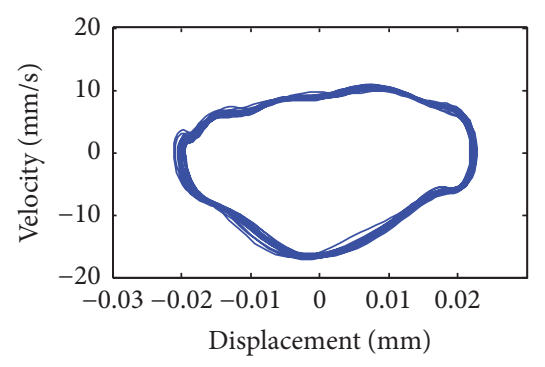

(c)

FIgURE 4: Acceleration and phase diagram in each stage: (a) stages A, C, and E; (b) stages B and F; (c) stage D.

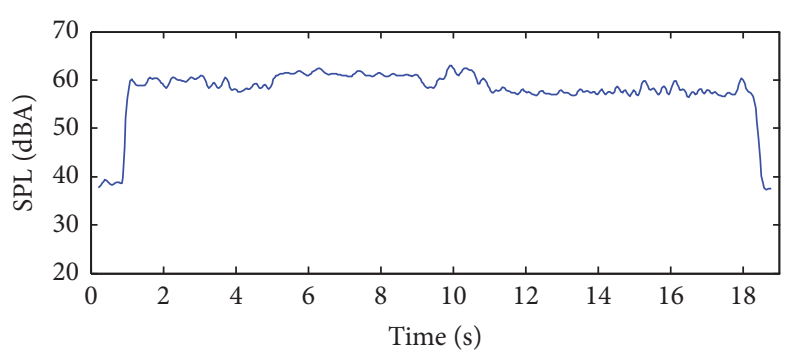

(a)

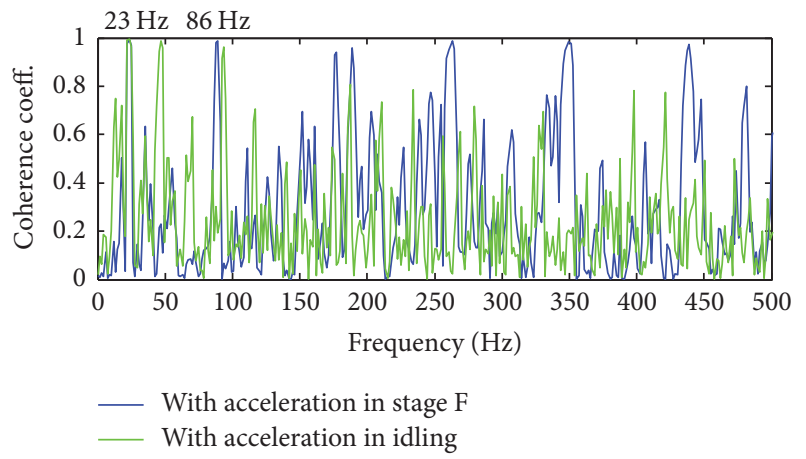

(b)

FIGURE 5: Characteristics of interior noise: (a) sound pressure level; (b) coherence coefficient with the acceleration of caliper in $X$ direction.

occurring, and the interior noise intensity is positively correlated with the vibration amplitude of the brake caliper except in stage E. The system is unstable in stage E, which is a transition stage from one stable status (stage D) to another stable status (stage F). Although the amplitude of the vibration in stage $\mathrm{E}$ is not the highest, its sound pressure level is the highest in the whole process. The coherence coefficient between caliper acceleration in $X$ direction and interior noise is shown in Figure 5(b). The blue curve is the coherence coefficient when creep groan occurs. The green curve is the coherence coefficient in idling; at this time, the interior noise is mainly caused by engine and creep groan does not occur. The frequency of $23 \mathrm{~Hz}$ corresponds to the second-order vibration of the engine, and the interior noise at this frequency is mainly caused by engine. When the vehicle is in idling, the coherence coefficients at $23 \mathrm{~Hz}$ and its multiple frequency are high. When creep groan occurs, the frequency of $86 \mathrm{~Hz}$ is the fundamental frequency of the creep groan; thus the coherence coefficients at $86 \mathrm{~Hz}$ and its multifrequency components are close to 1 , and it shows that, under this condition, the interior noise is mainly caused by the vibration of caliper. Therefore, the vibration of caliper can represent the dominant characteristics of creep groan.

From these figures and illustration, it can be seen that brake creep groan is a very complicated vibration. Although the pressure and rotational speed from $44 \mathrm{~s}$ to $62 \mathrm{~s}$ change a little, the accelerations of caliper change dramatically in different braking stage. This phenomenon was not reproduced and discussed in previous theoretical studies using finite element model. Meanwhile, it can be inferred that microcosmic motion of the brake components should be investigated, especially the contact status between pads and disc. From the frequency components, it can be seen that creep groan relates not only to the brake components but also to the other subsystems, such as suspension and driveline components. Therefore, a transient dynamic model for brake 

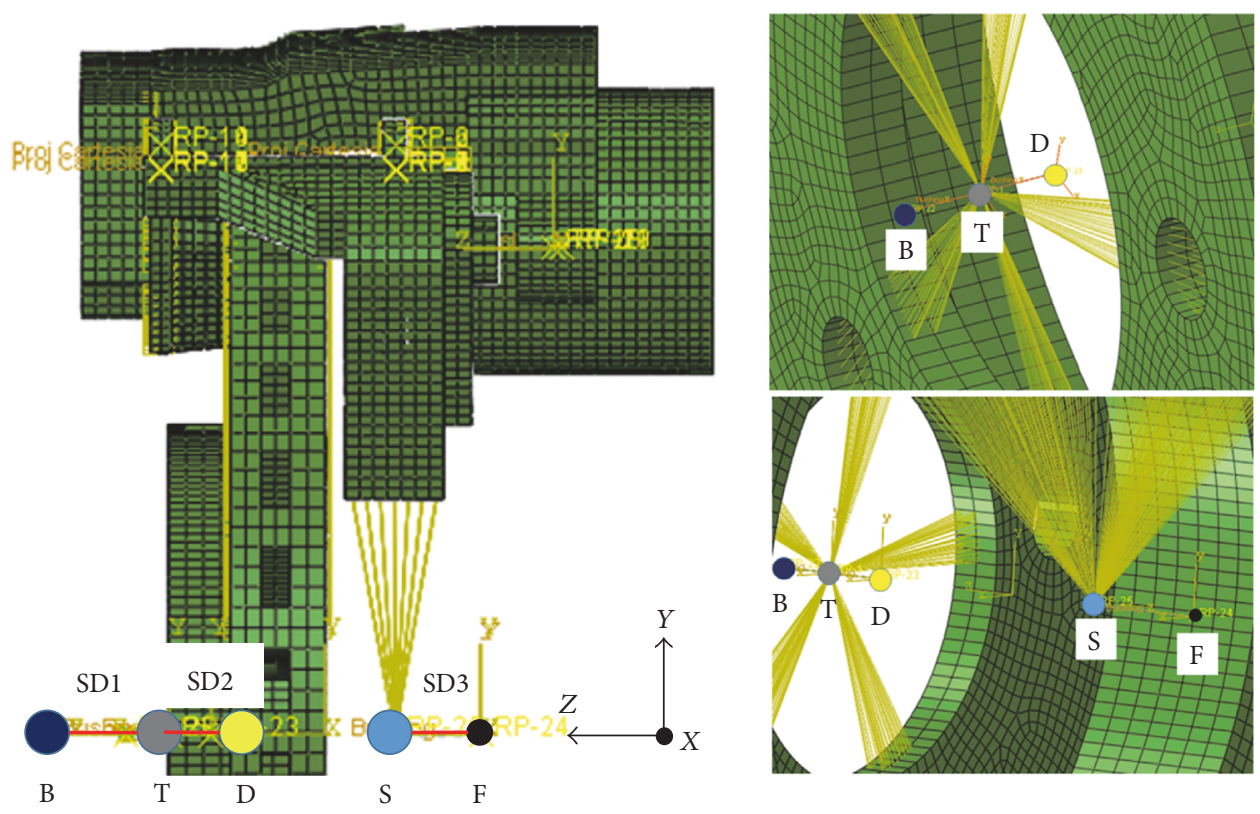

FIGURE 6: Topological structure of the FE model for creep groan analysis.

creep groan analysis could be accurately established by considering the subsystems and the structures of brake corner components.

\section{Transient Dynamic FE Modelling}

3.1. Topological Structure of the FE Model. In the previous studies, it has been found that brake creep groan is related to the components of brake, driveline system, suspension, and tire, which was documented in the reported experimental study. In order to fill the void in literatures, an object-oriented FE model of brake corner and subsystems is established. In order to simulate the contact status between pads and disc, the brake components are built as flexible bodies. Because the transient dynamic calculation in FEA costs a lot of time, the components of subsystems in the FE modelling are considered to be rigid bodies. According to mechanical vibration theory, the inertia, stiffness, and damping of the driveline, suspension, tire, and the vehicle body can be converted to proper quantities with respect to the rotation axis of the disc by an equivalent approach, which represent the dynamic parameters of these components. The topological structure of the FE model for creep groan analysis is shown in Figure 6.

In Figure 6, the brake assembly is flexible body and the modelling of brake assembly will be described next. The reference points $\mathrm{B}, \mathrm{T}, \mathrm{D}$, and $\mathrm{S}$ are rigid bodies, which represent the equivalent inertia of tire and vehicle body, the inertia of wheel hubs and rims, the equivalent inertia of driveline components, and the equivalent inertia of the suspension and knuckle, respectively. They only have the rotational degree of freedom around $z$-axis. The reference point $\mathrm{F}$ does not have mass and it is fixed to the ground. The reference points $\mathrm{B}$ and $\mathrm{T}$ are connected by SD1, which is a spring-damper element and represents the torsional stiffness and damping of tire. The reference points $\mathrm{T}$ and $\mathrm{D}$ are connected by SD2, which represents the equivalent torsional stiffness and damping of driveline system. The reference point $\mathrm{T}$ is coupled with the five bolt holes of disc. The reference point $S$ is coupled with the holes of guide pin in anchor. The reference points $\mathrm{S}$ and $\mathrm{F}$ are connected by $\mathrm{SD} 3$, which represents the equivalent stiffness and damping of suspension.

In order to establish the FE model of brake assembly, the wear between disc and pads and the changes of surface morphology of the contact surfaces are ignored. The FE model of the brake is mainly composed of hexahedral element and some local complex structures are composed of pentahedral element. The total number of the elements is 58971 and the total number of the nodes is 81339 . Because the vibration frequency of creep groan is usually lower than the minimum modal frequency of the brake components, the connections between the brake components are very important. Combined with the structures and the working principle of the brake, the connections are listed in Table 1. The roles of backplate, the rubber bushing of guide pin, and the leaf spring between backplate and anchor are included, as shown in Figure 7.

3.2. Key Parameters Definition. In the dynamic model, much equivalent inertia, stiffness, and damping should be calculated based on the structures of driveline, suspension, tire, and vehicle body. The inertia of the wheel hubs and rims $J_{\mathrm{T}}$ is calculated by their three dimensional model. The equivalent inertia of tire and vehicle body is given by $J_{\mathrm{B}}=$ $J_{\text {tire }}+0.5 m_{\mathrm{v}} r_{\text {tire }}$, where $J_{\text {tire }}$ and $r_{\text {tire }}$ are the inertia and radius of a tire, respectively, and $m_{\mathrm{v}}$ is the vehicle mass. The driveline inertia $J_{\mathrm{D}}$ represents the combined inertia of the engine inertia, the torque converter inertia, the inertia 
TABLE 1: Connections of brake components.

\begin{tabular}{lccc}
\hline Number & Parts & Relationship in actual structures & Connections in Abaqus \\
\hline$(1)$ & Disc, linings & Contact & Surf-to-surf contact (kinematic) \\
$(2)$ & Lining, backplate & Bond & Tie (node-to-surface) \\
$(3)$ & Backplate, piston & Contact & Surf-to-surf contact (penalty) \\
$(4)$ & Backplate, caliper finger & Contact & Surf-to-surf contact (penalty) \\
$(5)$ & Backplate, anchor & Leaf spring & Spring \\
$(6)$ & Piston, caliper & Contact & Surf-to-surf contact (penalty) \\
$(7)$ & Anchor, guide pin & Thread & Tie (node-to-surface) \\
$(8)$ & Caliper, guide pin & Rubber bushing & Bushing connector \\
\hline
\end{tabular}

TABle 2: Parameters of the inertia, stiffness, and damping in the model.

\begin{tabular}{lccccc}
\hline Points & Equivalent parts & Inertia $\left(\mathrm{kg} \mathrm{m}^{2}\right)$ & Torsional stiffness $(\mathrm{Nm} / \mathrm{rad})$ & Translational stiffness $(\mathrm{N} / \mathrm{m})$ & Damping $(\mathrm{N} \mathrm{ms} / \mathrm{rad})$ \\
\hline $\mathrm{B}$ & Tire and vehicle body & $J_{\mathrm{B}}=72.08$ & $K_{\mathrm{B}}=22500$ & - & - \\
$\mathrm{T}$ & Tire hubs and rims & $J_{\mathrm{T}}=0.579$ & - & - & - \\
$\mathrm{D}$ & Driveline system & $J_{\mathrm{D}}=9.3$ & $K_{\mathrm{D}}=8900$ & - & $C_{\mathrm{D}}=1.6$ \\
$\mathrm{~S}$ & Suspension and knuckle & $J_{\mathrm{S}}=0.1$ & $K_{\mathrm{S}}=65000$ & - & $C_{\mathrm{S}}=4.53$ \\
- & Rubber bushing & - & $k_{R X}=k_{R Y}=2.5$ & $k_{X}=k_{Y}=5000$ & $c_{X}=c_{Y}=0.2$ \\
- & Leaf spring & - & - & $k_{X}=1600$ & - \\
& & & & $k_{Y}=3000$ & - \\
\hline
\end{tabular}

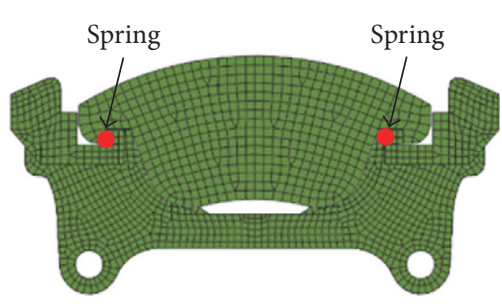

(a)

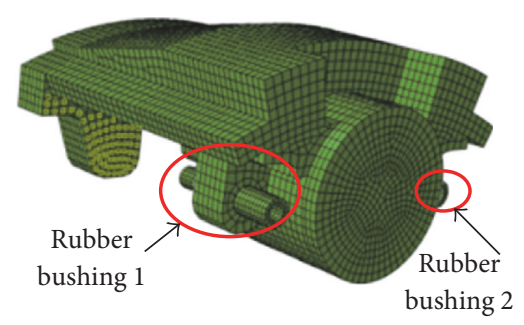

(b)

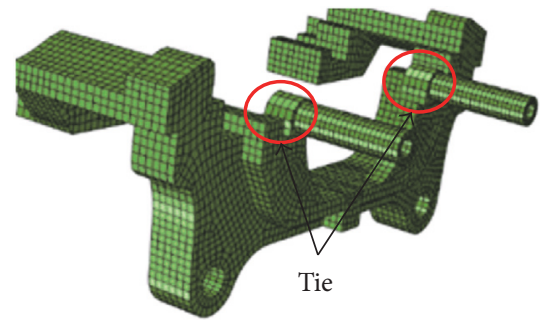

(c)

FIGURE 7: Connections of the key brake components: (a) springs between backplate and anchor; (b) rubber bushings between caliper and guide pin; (c) threads between anchor and guide pin.

of the transmission input and output components, and the inertia of the final drive pinion and axle shaft. The structure of suspension and knuckle is very complex and is approximated as a rotor with the equivalent inertia $J_{S}$ being calculated. The equivalent stiffness $K_{\mathrm{D}}$ and damping $C_{\mathrm{D}}$ of the driveline include the stiffness and damping of the transmission input and output shafts and axle shaft. For the calculation method of $J_{\mathrm{D}}, J_{\mathrm{S}}, K_{\mathrm{D}}$, and $C_{\mathrm{D}}$, the reader is referred to paper [17]. The equivalent torsional stiffness and damping of tire and suspension are calculated according to the K\&C test results of suspension under condition of braking force loading. The parameters of the inertia, stiffness, and damping are summarized in Table 2 .

The material of most components in the FE model is considered to be uniform and isotropic, but the material of friction lining is anisotropic. The material properties of components are given in Table 3, and they do not change with temperature. These material properties are used for the modal analysis of each component, and the simulation results are verified by modal test. The stiffness and damping of the rubber bushing around the guide pin and the leaf spring are calculated by FE method. The FE model of rubber bushing is built based on a hyperelastic-viscoelastic-elastoplastic model of rubber material. Mooney-Rivlin model is used in the hyperelastic model and the 3-order Prony series is used in the viscoelastic model. The stiffness and damping of the rubber bushing and leaf spring are also given in Table 2.

The difference between the dynamic and static friction coefficient is the root cause of stick-slip motion; as such it is very important to obtain the friction coefficient of the brake for the simulation. Due to the brake friction coefficient varying with the rotational speed, pressure, temperature, and contact surface morphology, it is necessary to measure the brake friction coefficient level in vehicle. The test setup is shown in Figure 8. An adjustment level is perpendicular to the ground, and a driver in the car applies braking slowly to a specific oil pressure, which is measured by the oil pressure sensor, and then the driver keeps the pressure as stable as 
TABLE 3: Material properties of the brake components.

\begin{tabular}{lcccc}
\hline Parts & Density $\left(\mathrm{kg} \mathrm{m}^{-3}\right)$ & Young's modulus $(\mathrm{GPa})$ & Shear modulus $(\mathrm{GPa})$ & Poisson's ratio \\
\hline Disc & 7310 & 135 & - & 0.23 \\
Backplate & 7880 & 200 & - & 0.27 \\
Caliper & 7120 & 159 & - & 0.27 \\
Piston & 7860 & 105 & - & 0.30 \\
Anchor & 7540 & 190 & - & 0.26 \\
Guide pin & 7800 & 135 & $G_{13}=G_{23}=2.50$ & 0.30 \\
Lining & 3080 & $E_{x}=E_{y}=15.1$ & $G_{12}=4.30$ & $V_{12}=V_{21}=V_{31}=V_{32}=0.14$ \\
& & $E_{z}=1.50$ & & $V_{23}=V_{13}=0.40$ \\
\hline
\end{tabular}

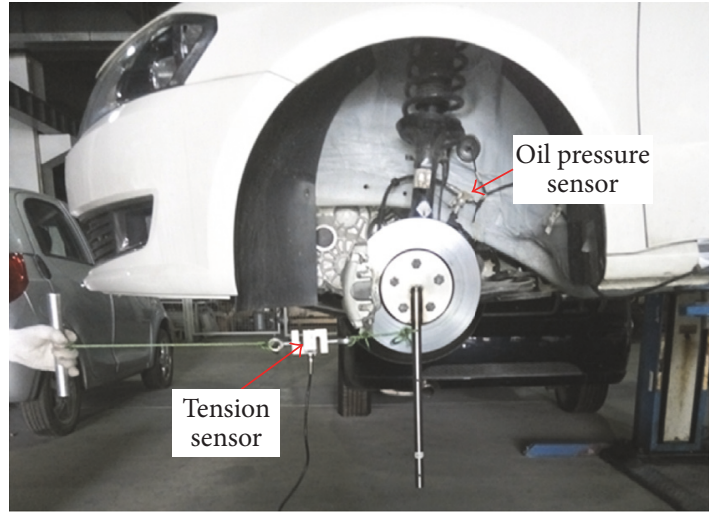

FIGURE 8: Test setup for the brake friction coefficient.

possible. A tester slowly increases the tension of adjustment level in horizontal direction, until the disc begins to rotate. The rotation angle of the level is less than 10 degrees. In the test, creep groan always occurs.

Figure 9 shows the time history curves of tension and oil pressure. In Figure 9, brake pressure changes slightly, and the tension increases dramatically from $3.5 \mathrm{~s}$ to $12 \mathrm{~s}$, and the disc remains static in this stage. After $12 \mathrm{~s}$, the tension oscillates strongly and creep groan occurs. In the stage of stick, the tension increases rapidly to the maximum of static friction force. At the moment the disc starts to move, the tension drops suddenly. Then, in the stage of slip, the tension fluctuates periodically. The maximum and minimum of the tension in one period are considered to correspond to the maximum of static friction force and the dynamic friction force. At the same time they correspond to the oil pressures variation. Combined with the evaluated radius of piston, the equivalent brake radius, and the level arm, the friction coefficient can be calculated. Repeat the test for 6 times under identical oil pressure; the average value of the test results is obtained. Table 4 shows the test results under the condition of pressure of 8 bar, and the standard deviation of the static and dynamic friction coefficients is very small, which exhibits that the accuracy of the results can be accepted. The test results are used for the friction coefficient model of the brake FE model, as shown in equation $\mu=\mu_{d}+\left(\mu_{s}-\mu_{d}\right) e^{-d v}$, where $d$ is the attenuation factor and $v$ is relative speed of the contact points.

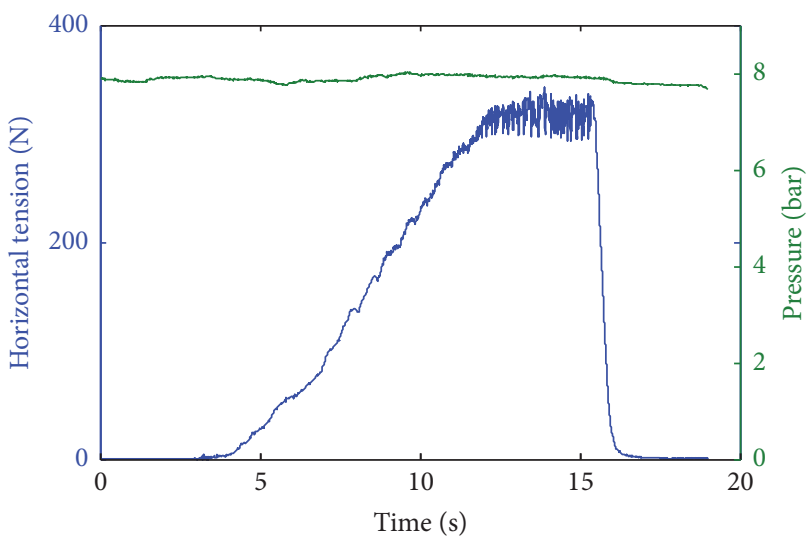

Figure 9: Curves of tension and oil pressure.

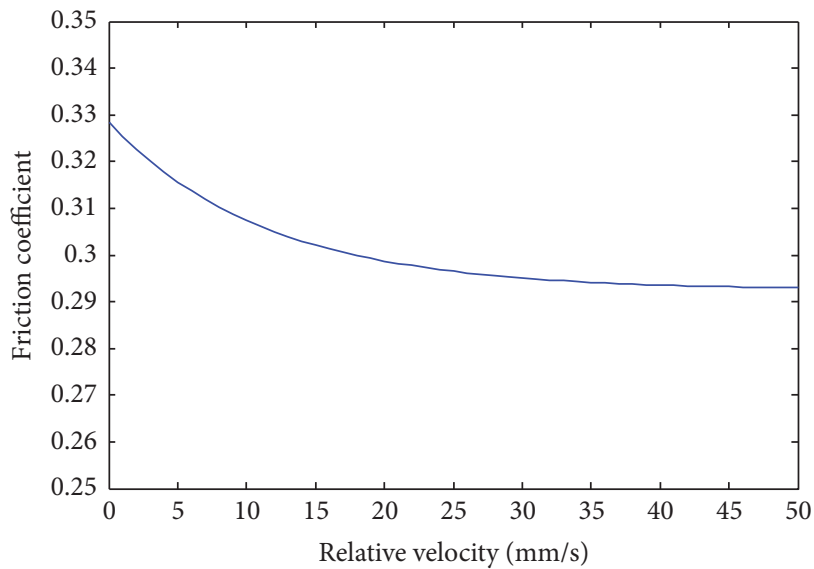

FIGURE 10: Friction coefficient curve in the model.

While the static friction coefficient $\mu_{s}=0.3283$ and the dynamic friction coefficient $\mu_{d}=0.2925$ and $d=0.0813$ are input in the equation, the curve of brake friction coefficient is shown in Figure 10.

3.3. Simulation Condition and Setup. The simulation condition is selected to be the same as the test condition when creep groan occurs. The driving force in the test is the gravitational component along the direction of the ramp, and the driving force remains constant when the slope angle is assumed to be 
TABLE 4: Friction coefficient under condition of oil pressure of 8 bar.

\begin{tabular}{|c|c|c|c|c|c|c|c|c|}
\hline Times & 1 & 2 & 3 & 4 & 5 & 6 & Average & Standard deviation \\
\hline Oil pressure (bar) & 7.92 & 7.93 & 7.93 & 7.92 & 7.91 & 7.90 & 7.92 & 0.01 \\
\hline Maximum of tension $(\mathrm{N})$ & 249.00 & 249.90 & 251.90 & 251.80 & 253.20 & 251.80 & 252.87 & 2.21 \\
\hline Minimum of tension $(\mathrm{N})$ & 223.10 & 226.70 & 224.20 & 223.30 & 225.10 & 227.00 & 225.36 & 1.57 \\
\hline Static friction coefficient & 0.3221 & 0.3228 & 0.3253 & 0.3260 & 0.3286 & 0.3271 & 0.3283 & 0.0036 \\
\hline Dynamic friction coefficient & 0.2886 & 0.2928 & 0.2896 & 0.2891 & 0.2921 & 0.2949 & 0.2925 & 0.0025 \\
\hline
\end{tabular}

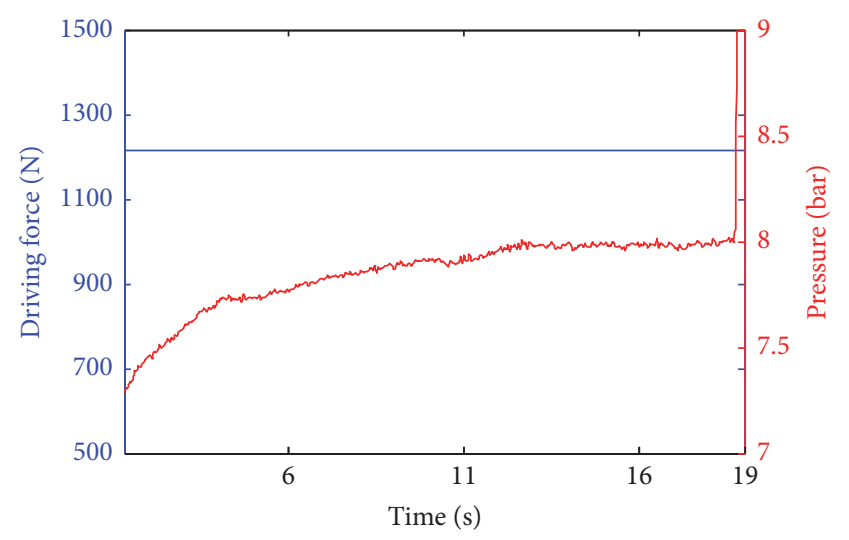

FIGURE 11: Driving force and brake pressure in the vehicle.

constant. Creep groan is investigated in detail from $44 \mathrm{~s}$ to $62 \mathrm{~s}$ in the vehicle test; thus the brake pressure and driving force in this stage, as shown in Figure 11, are used to calculate the angular velocity of the disc. Figure 11 shows that the driving force and brake pressure are nearly steady after $15 \mathrm{~s}$, and it can be assumed that after $15 \mathrm{~s}$ the driving force is balanced with the braking force; thus the ratio between brake pressure and braking force can be calculated. Using this ratio, the angular velocity of the disc from $44 \mathrm{~s}$ to $62 \mathrm{~s}$ can be calculated, which increases linearly to $0.2 \mathrm{rad} / \mathrm{s}$ after 2.2 seconds and then rotates uniformly. Due to the fact that simulation speed in the FE model is very low, the simulation is implemented for 2.2 seconds. The curves of brake pressure and angular velocity used in the simulation are shown in Figure 12. The brake pressure is applied on the bottom surfaces of piston and the piston cavity to simulate the braking force, and the angular velocity is applied on point $\mathrm{D}$ as shown in Figure 6 to simulate the driving force.

\section{Results and Discussion}

4.1. Macroscopic Stick-Slip Motion. Stick-slip motion is the basic evaluation criteria of the occurrence of creep groan, and it can be presented by the tangential velocities of disc and lining, as shown in Figure 13. The fluctuation of the angular velocities in $0.05 \mathrm{~s}$ is caused by the simulation step of application of brake pressure within $0.01 \mathrm{~s}$ and the system is not unstable. From $0.05 \mathrm{~s}$ to $0.2 \mathrm{~s}$, the disc does not rotate because the driving force is lower than braking force. From $0.2 \mathrm{~s}$ to $0.6 \mathrm{~s}$, the disc begins to rotate and the angular velocities of disc and lining are equal, because the static

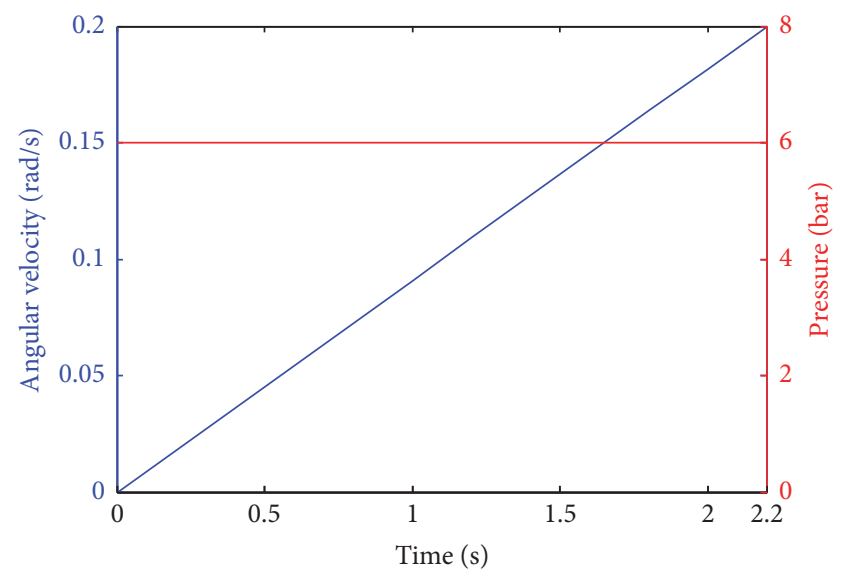

FIGURE 12: Curves of angular velocity and brake pressure used in the simulation.

friction force between disc and lining is larger than the spring force between backplate and anchor and no relative movement exists between the disc and lining. When the spring force between backplate and anchor is larger than the static friction force, the lining can move relatively to the disc after $0.6 \mathrm{~s}$.

Partial time history curves are zoomed in and used to exhibit a typical periodic stick-slip motion, which elaborates the occurrence of creep groan. In the entire time history curves of the tangential velocity, the stick-slip motion consists of several stages. Stage A is from $0.9 \mathrm{~s}$ to $1.6 \mathrm{~s}$ and stage B is from $1.8 \mathrm{~s}$ to $2.2 \mathrm{~s}$, and there are transition stages from $0.6 \mathrm{~s}$ to $0.9 \mathrm{~s}$ and from $1.6 \mathrm{~s}$ to $1.8 \mathrm{~s}$. In stage $\mathrm{A}$, the period of creep groan and the magnitude of tangential velocity fluctuation of disc are larger than those in stage B; and the time in sticking is longer than that in slipping, which is opposite to the case in stage B; the direction of tangential velocity of disc can be opposite to the direction of angular speed set in the model, but in stage B it is always the same as the direction of the angular speed. Figure 14 shows the phase diagram of the lining in tangential direction with obvious limit cycles generated both in the two stages, which further proves the occurrence of the creep groan. But the features of phase diagram in the two stages are different. The phase diagram in stage A shows a typical double-period motion, but it evolves into a single-period motion in stage $\mathrm{B}$. The characteristics of creep groan are similar in the test results, and the transient dynamic model can be used to generate different type of stickslip motion in one braking. 


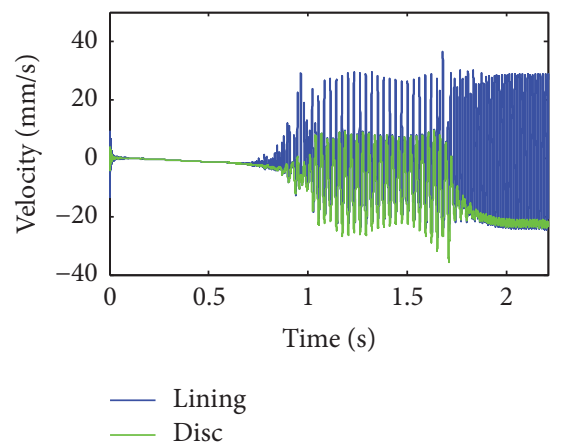

(a)

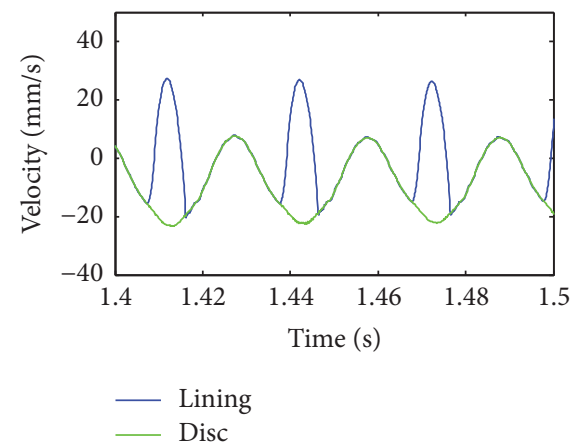

(b)

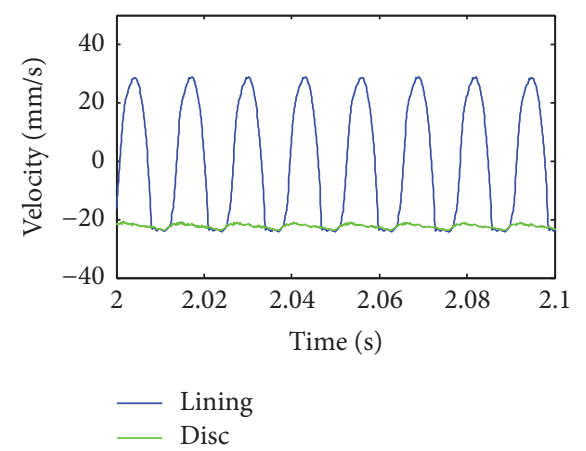

(c)

Figure 13: Time history curves of tangential velocity of disc and lining.

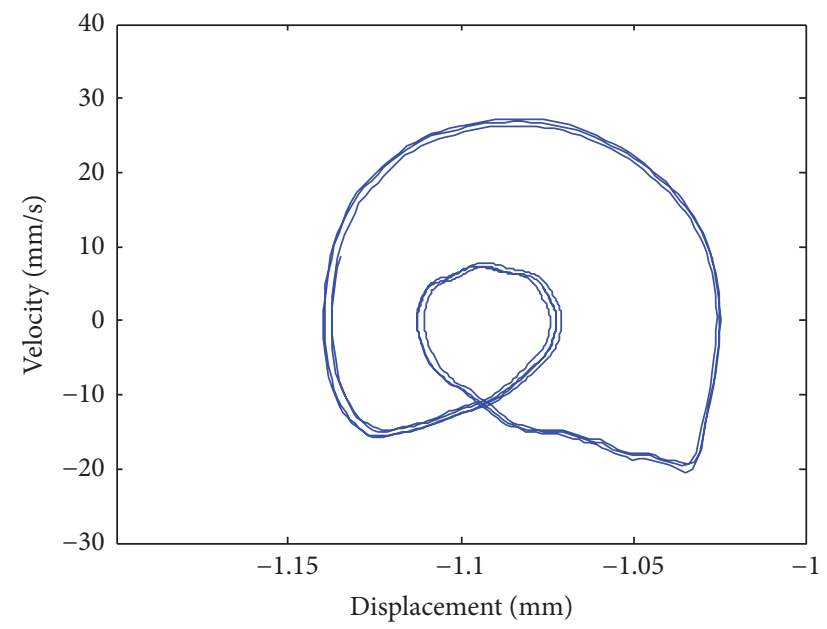

(a)

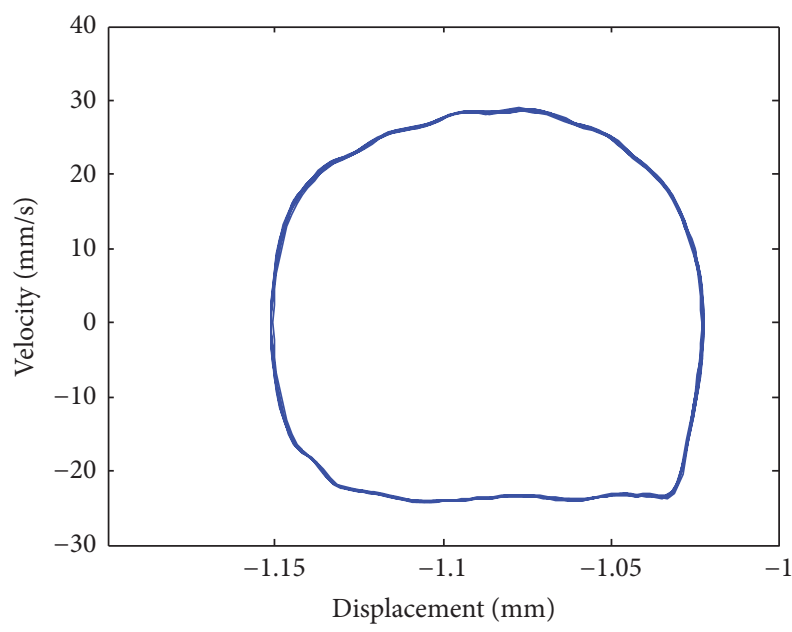

(b)

FIgURE 14: Phase diagram of lining in tangential direction: (a) stage A; (b) stage B.

Although the macroscopic stick-slip motion is related to the relationship between friction coefficient and relative speed (between disc and linings), the energy of input and dissipation and their transformation need to be studied for further understanding of the creep groan mechanism, which is shown in Figure 15. Due to the uniform accelerating rotation of the disc, the energy is input into the system continuously and the input power increases with the braking time. The input energy can transform into the kinetic energy, elastic strain energy, friction dissipation energy, and viscous dissipation energy. The kinetic energy and viscous dissipation energy are small, and most of input energy are transformed into elastic strain energy and dissipated by the effect of friction. In the process of stick, the friction force is the internal force and no energy is dissipated by friction; thus the curve of friction dissipation energy is nearly flat. Meanwhile, the input energy is almost transformed into elastic strain energy, so that the curve of elastic strain energy increases sharply. In the process of slip, due to the effect of friction and damping, the friction dissipation energy increases and the elastic strain energy decreases. Under this mechanism of energy transformation, the stick-slip motions occur continuously.

4.2. Microcosmic Stick-Slip Motion. Based on the FE modelling of brake components, the contact state and friction behavior between disc and linings can be analyzed in detail, which cannot be measured during braking testing. The analysis and simulation may give us some new understanding of creep groan. Depending on the shape of lining, brake force, and relative speed, each node on the contact surface of lining may be sticking, slipping, or separation. When the relative speed between one node and its counter surface is not larger than $10^{-10} \mathrm{~mm} / \mathrm{s}$ with the distance smaller than $10^{-10} \mathrm{~mm}$ in $Z$ direction, the contact state of the node is defined as sticking, and otherwise it is defined as slipping. When the distance between the node and its counter surface is not smaller than $10^{-10} \mathrm{~mm}$ in $Z$ direction, the contact state of the node is defined as separation.

Figure 16 shows the contact state of the nodes on the surface of inner lining in a period from stick to slip. The surface of the lining does not contact with the disc integrally. 


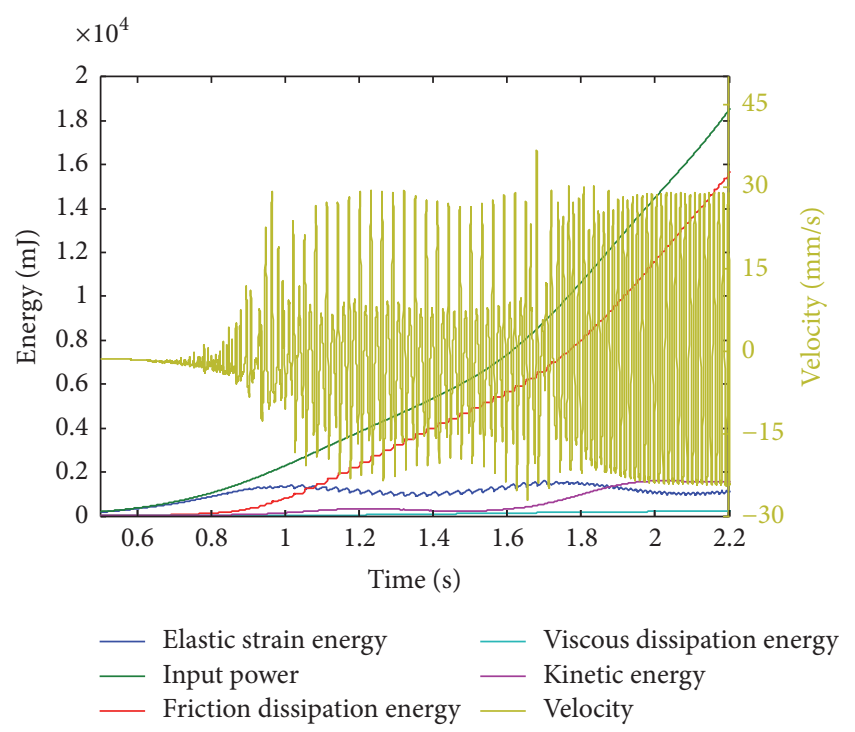

FIGURE 15: Energy of input, dissipation, and transformation in the stick-slip motion.

Actually, some of the nodes in the trailing area separate with the disc. At $1.5001 \mathrm{~s}$, the disc and lining are in the process of stick, in which most of the nodes on the contact surface are in the state of sticking, but some nodes in the edge area begin to slip due to the small contact pressure in this area, as shown in Figure 16(a). At $1.5002 \mathrm{~s}$, the disc and lining begin to slip, and most of the sticking nodes transform into the state of slipping. But many nodes still keep the state of sticking, as shown in Figure 16(b). At $1.5003 \mathrm{~s}$, the disc and lining are in the stage of slip, and all of the sticking nodes are transferred to be the state of slipping. Therefore, it can be concluded that the microcosmic contact status at the friction interface causes the macroscopic stick-slip motion of the lining.

Most of the nodes at the friction surface change the contact state repeatedly, and it is bound to affect the friction coefficient. Figure 17(a) shows the microcosmic friction coefficient of a single node, which contacts with the disc surface all the time in braking. Figure 17(b) shows the macroscopic friction coefficient of the lining. From Figures 17(a) and 17(b), it can be seen that the microcosmic and macroscopic friction coefficients increase in the early stage and then fluctuate in the following stage, but the start time of the fluctuation is different. Within the earliest $0.5 \mathrm{~s}$, the microcosmic and macroscopic friction coefficients are approximately equal. From $0.5 \mathrm{~s}$ to $0.6 \mathrm{~s}$, the microcosmic friction coefficient increases sharply to the maximum of static friction coefficient, because no relative speed exists between the disc and lining before $0.6 \mathrm{~s}$, as shown in Figure 13(a). From $0.6 \mathrm{~s}$ to $0.9 \mathrm{~s}$, the macroscopic friction coefficient keeps increasing and reaches the maximum, but in this stage the macroscopic friction coefficient is much smaller than the microcosmic friction coefficient. It can be correlated with the contact status between lining and disc, in which some nodes of lining separate with disc, as shown in Figure 16. The maximum of the microcosmic friction coefficient is 0.328 , and it is higher than the maximum of macroscopic friction coefficient of 0.31 . The macroscopic friction coefficient is the result of the integration of all the nodes at the friction surface, which is affected by the contact status of each node. Since all of the nodes cannot reach the maximum of the static friction coefficient at the same time, the maximum of the macroscopic friction coefficient is lower than the maximum of the microcosmic friction coefficient, which is the same as the friction coefficient maximum in Figure 10.

After reaching the maximum, the microcosmic and macroscopic friction coefficients begin to fluctuate. The macroscopic friction coefficient fluctuation shows a typical characteristic of stick-slip motion, which is not shown in the microcosmic friction coefficient. The macroscopic friction coefficient can be divided into two stages from $1.6 \mathrm{~s}$, and it is similar to the characteristic of tangential velocity of the lining. Therefore, the microcosmic friction coefficient of node is different from the macroscopic friction coefficient of lining, and it may affect the spatial motion of the lining.

4.3. Spatial Motion of Lining. For the creep groan problem, the existing research of spatial motion of lining and caliper is rare and their effects on the stick-slip motion need to be studied. Five nodes on the friction surface of inner lining are chosen for investigation, as shown in Figure 18. It is supposed that half of the surface of the inner lining near the leading edge is the leading area, and the other half surface is the trailing area. Nodes 1 and 5 are in the leading area, and nodes 2 and 4 are on the side of the trailing edge, and node 3 is at the center of the lining. $P_{1}$ and $P_{2}$ are supposed to be the contact pressure center in the leading and trailing areas, respectively.

Spatial motion of inner lining in $X$ and $Z$ directions is shown in Figure 19. Figure 19(a) exhibits that inner lining moves along the rotation direction integrally before $0.9 \mathrm{~s}$, which is opposite to $X$ direction. There are component forces in $X$ direction of friction forces with disc; thus the lining has a translational movement opposite to $X$ direction. After $0.9 \mathrm{~s}$, the displacement of lining fluctuates, as shown in Figure 19(b), and it is caused by the stick-slip motion of lining. In $Z$ direction, the lining moves to the disc surface and results in elastic deformation under the action of brake pressure; thus the lining has a translational movement along $Z$ direction. Subject to the trend of the movement, the fluctuation of displacement in $Z$ direction can be attained, and partial curves are shown in Figure 19(c). Compared with the displacements of nodes 1 to 5 in $Z$ direction, the direction of displacement fluctuation of nodes 1 and 5 is opposite to that of nodes 2 and 4, which suggests that a torsional vibration around $Y$ direction is generated. From Figure 16, it can be inferred that contact pressure at $P_{1}$ and $P_{2}$ changes when the stick-slip motion occurs, and this leads to the torsional vibration of lining around $Y$ direction.

Figure 20 shows the displacements of the five nodes in $Y$ direction. From $0.1 \mathrm{~s}$ to $0.6 \mathrm{~s}$, nodes 1 and 5 move along $Y$ direction, but nodes 2 and 4 move oppositely to the $Y$ direction, and node 3 almost does not move. It can be seen that the lining has a rotational movement in the plane of $X Y$. From $0.6 \mathrm{~s}$ to $0.9 \mathrm{~s}$, the five nodes move along the $Y$ direction integrally, and the displacements fluctuate after 0.9 s. The direction of displacement fluctuation of nodes 1 


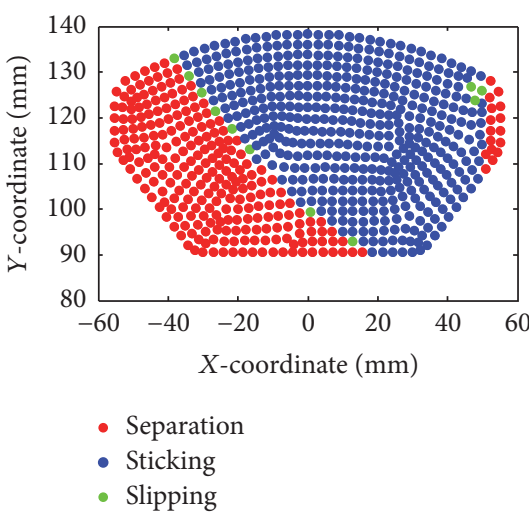

(a)

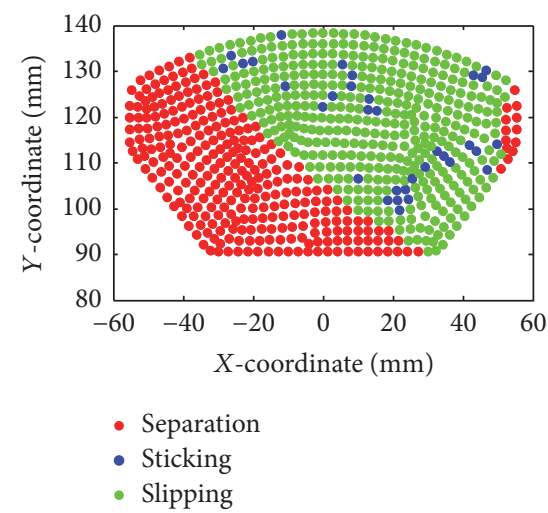

(b)

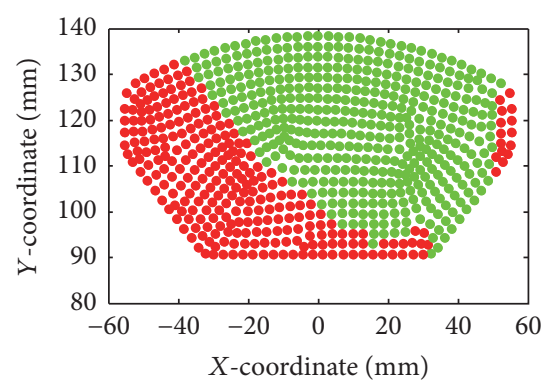

- Separation

- Slipping

(c)

FIGURE 16: Contact state of the nodes on the surface of inner lining: (a) $1.5001 \mathrm{~s}$; (b) $1.5002 \mathrm{~s}$; (c) $1.5003 \mathrm{~s}$.

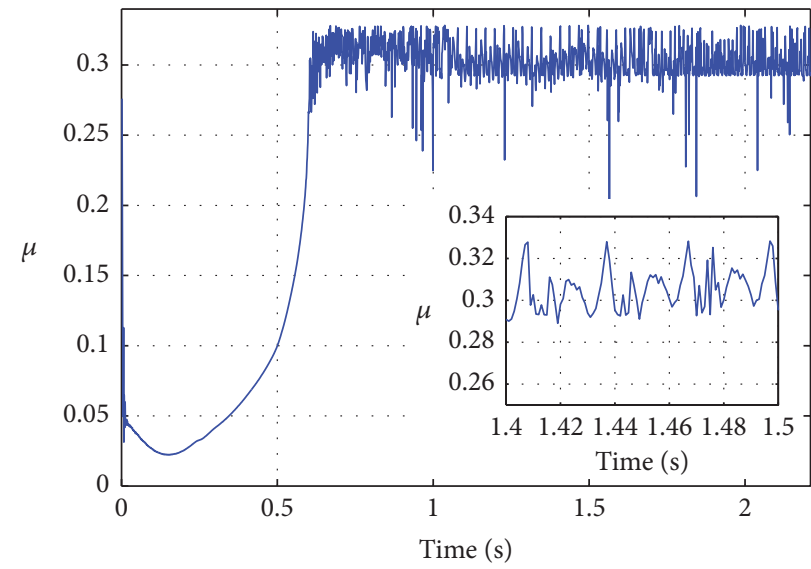

(a)

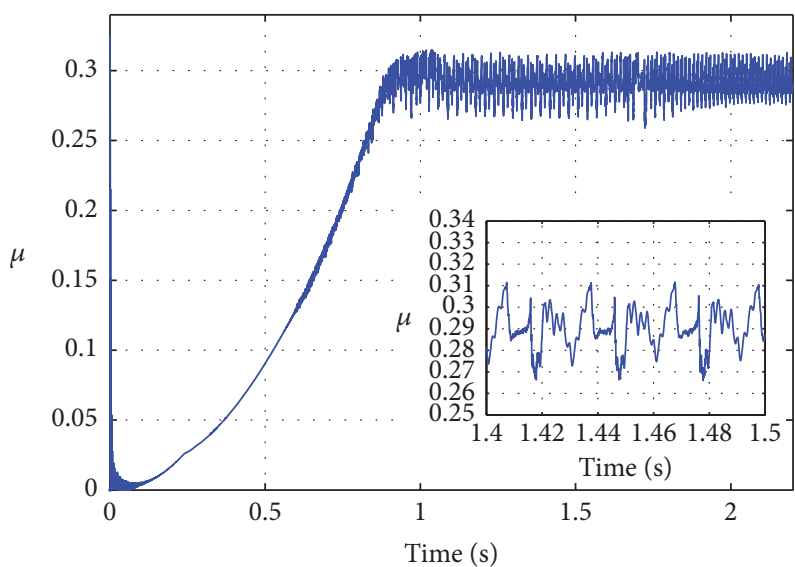

(b)

FIGURE 17: Friction coefficient calculated in the simulation: (a) microcosmic friction coefficient of a single node on the friction surface; (b) macroscopic friction coefficient of the lining.

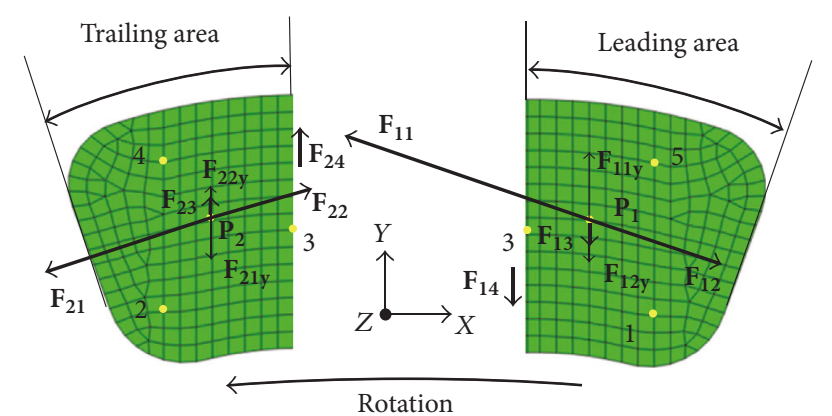

FIGURE 18: Diagram of the mechanism of spatial motion of inner lining.

and 5 is opposite to that of nodes 2 and 4, and the amplitude of fluctuation of node 3 is the lowest. Therefore, a torsional vibration occurs in the plane of $X Y$.

In order to find the reason of the spatial motion of lining in $Y$ direction, a schematic diagram of forces on lining is shown in Figure 18. $F_{11}$ and $F_{21}$ are supposed to be the resultant force of the friction force with disc in the leading and trailing areas, and $F_{12}$ and $F_{22}$ are supposed to be the resultant force of the friction force with piston in the leading and trailing areas. $F_{11 y}, F_{12 y}, F_{21 y}$, and $F_{22 y}$ are component forces in $Y$ direction of $F_{11}, F_{12}, F_{21}$, and $F_{22}$. Because there exists no relative speed between disc and lining before $0.6 \mathrm{~s}$, as shown in Figure 13(a), it can be inferred that the friction force with disc is larger than the friction force with piston, as given as follows:

$$
\begin{gathered}
\left|F_{11}\right|>\left|F_{12}\right|, \\
\left|F_{11 y}\right|>\left|F_{12 y}\right|, \\
\left|F_{21}\right|>\left|F_{22}\right|, \\
\left|F_{21 y}\right|>\left|F_{22 y}\right| .
\end{gathered}
$$

Therefore, nodes 1 and 5 in leading area tend to move in $Y$ direction and nodes 2 and 4 in trailing area tend to move 


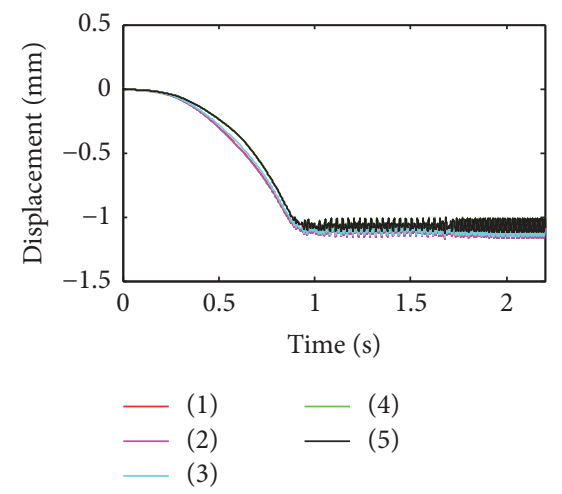

(a)

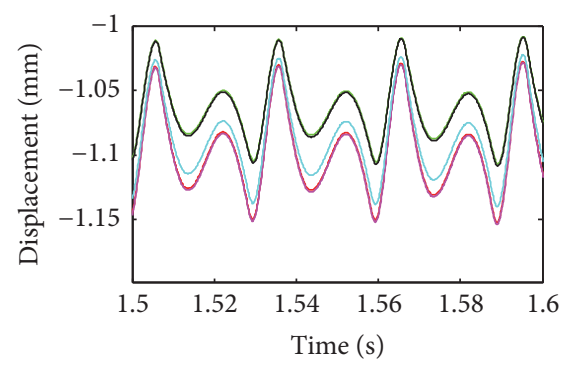

(1) - (4)

(2) - (5)

(3)

(b)

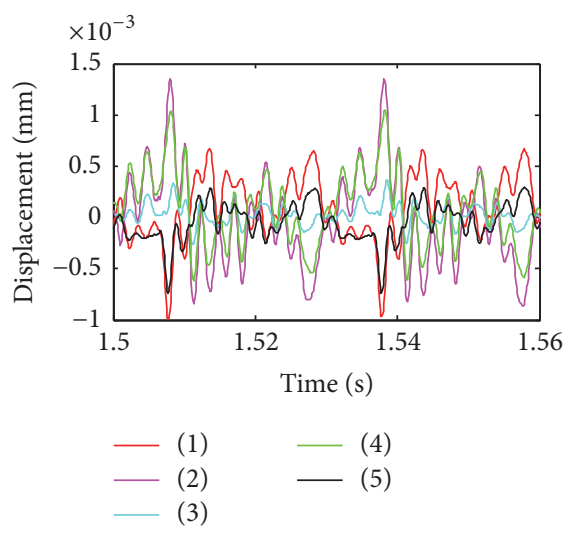

(c)

FIGURE 19: Spatial motion of five nodes on inner lining in $X$ and $Z$ directions: ((a) and (b)) time history curves and partial magnification of displacement in $X$ direction; (c) partial magnification of displacement in $Z$ direction.

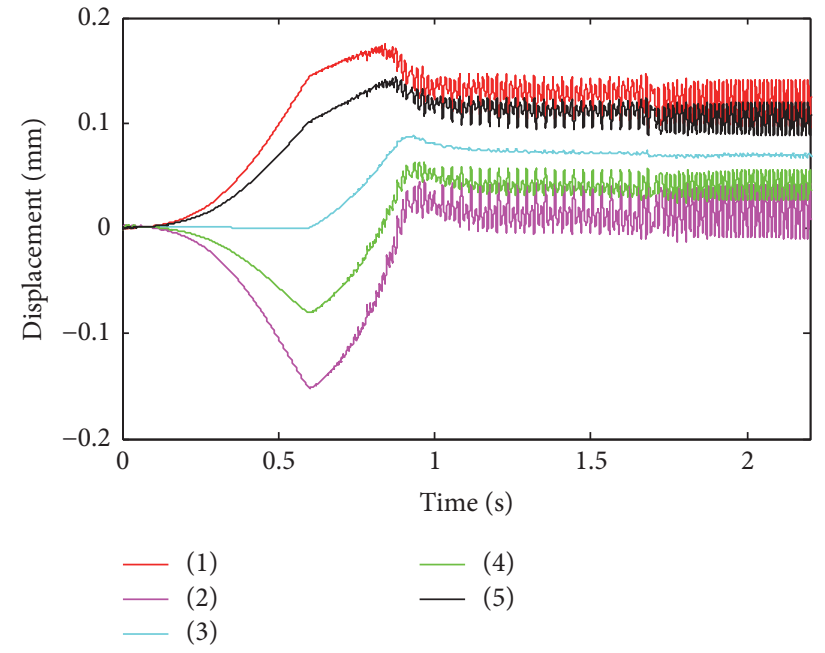

(a)

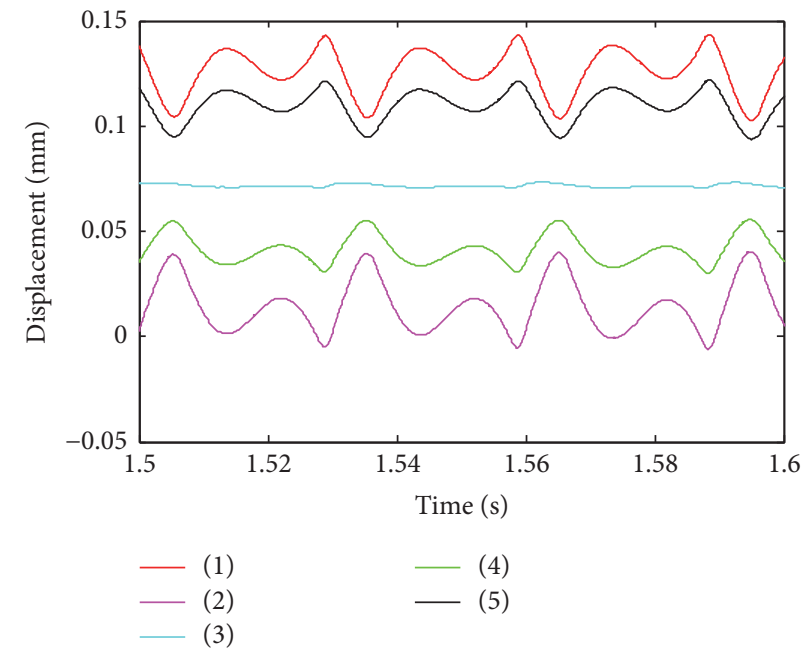

(b)

Figure 20: Spatial motion of five nodes on inner lining in $Y$ direction: (a) time history curves; (b) partial curves.

opposite to $Y$ direction from $0.1 \mathrm{~s}$ to $0.6 \mathrm{~s}$. In this case, there are two resistance $F_{13}$ and $F_{23}$ from disc and piston, and a pair of action and reaction forces $F_{14}$ and $F_{24}$ between the parts of leading and trailing. These forces are subject to the following inequality:

$$
\begin{aligned}
& \left|F_{11 y}\right|>\left|F_{12 y}\right|+\left|F_{13}\right|+\left|F_{14}\right|, \\
& \left|F_{21 y}\right|>\left|F_{22 y}\right|+\left|F_{23}\right|+\left|F_{24}\right| .
\end{aligned}
$$

Due to the rotational movement in the $X Y$ plane, the contact status with disc changes. After $0.6 \mathrm{~s}$, the contact pressure in leading area increases and the contact pressure in trailing area decreases, so that the contact area in leading area is larger than that in trailing area, as shown in Figure 16. Then $F_{11}$ increases and $F_{21}$ decreases, which could result in $F_{24}$ becoming larger than $F_{21 y}$, so that the nodes in trailing area move along $Y$ direction. Under this condition, $F_{23}$ changes its direction and the relationship of the forces in trailing area can be given in (3). Therefore, the five nodes move along the $Y$ direction integrally from $0.6 \mathrm{~s}$ to $0.9 \mathrm{~s}$.

$$
\left|F_{22 y}\right|+\left|F_{24}\right|>\left|F_{21 y}\right|+\left|F_{23}\right| \text {. }
$$

Moreover, the inflection points of the nodes displacements occur at $0.6 \mathrm{~s}$ and $0.9 \mathrm{~s}$, and the inflection points are the same as those of the microcosmic and macroscopic friction coefficients in Figure 17; thus it can be inferred that the microcosmic friction coefficient plays an important role in the movement of lining before $0.6 \mathrm{~s}$, and macroscopic friction coefficient affects the movement of lining after $0.6 \mathrm{~s}$.

After $0.9 \mathrm{~s}$, the lining moves to a new static equilibrium position and then torsional vibration occurs in the plane of $X Y$. In order to find the reason for these phenomena, the displacements of the five nodes in $Y$ direction and the tangential speed of lining and disc are plotted together, as 


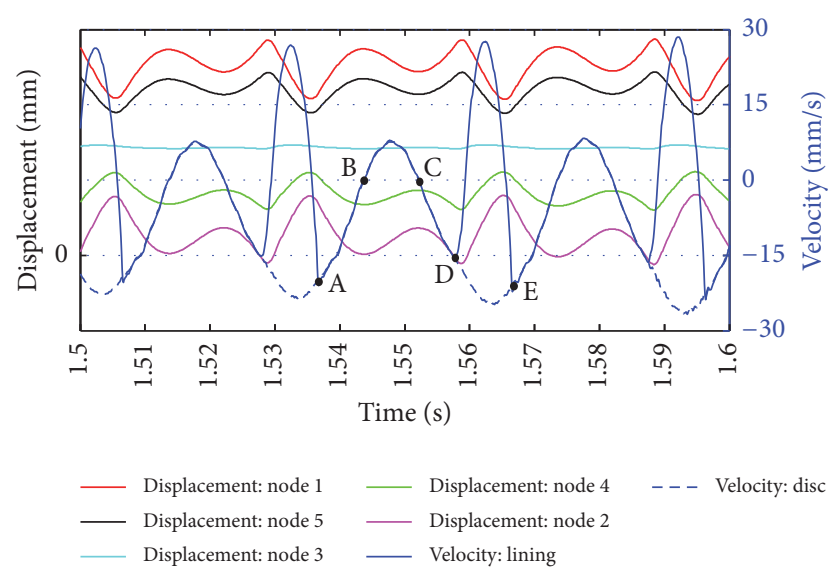

FIGURE 21: Relationship between displacement of lining in $Y$ direction and the tangential speed of lining and disc.

shown in Figure 21. The curves in the period from $1.537 \mathrm{~s}$ (point A) to $1.566 \mathrm{~s}$ (point $\mathrm{E}$ ) are further discussed as follows. In the stage from $1.537 \mathrm{~s}$ (point $\mathrm{A}$ ) to $1.544 \mathrm{~s}$ (point $\mathrm{B}$ ) and the stage from $1.552 \mathrm{~s}$ (point $\mathrm{C}$ ) to $1.558 \mathrm{~s}$ (point $\mathrm{D}$ ), the lining is in sticking and the tangential speeds of disc and lining are opposite to the $X$ direction. Because the direction of the friction forces on lining is the same as the direction of disc tangential speed, in these stages, the forces on lining are the same as those in Figure 19 and they are subject to (2); thus the displacements of nodes 1 and 5 increase and the displacements of nodes 2 and 4 decrease. From $1.544 \mathrm{~s}$ (point B) to $1.552 \mathrm{~s}$ (point $\mathrm{C}$ ), the lining is still in sticking, but the tangential speeds of lining and disc are along the $X$ direction, and the directions of forces on lining are opposite to those in Figure 19; thus the displacements of nodes 1 and 5 decrease and the displacements of nodes 2 and 4 increase. From $1.558 \mathrm{~s}$ (point D) to $1.566 \mathrm{~s}$ (point E), although the tangential speeds of disc are opposite to the $X$ direction and the directions of forces on lining are the same as those in Figure 19, the lining is in slipping and the static friction coefficient changes to the dynamic friction coefficient. Therefore, $F_{11}$ and $F_{21}$ decrease, and the resultant forces in $Y$ direction of leading area and trailing area reverse their directions. Moreover, the displacements of nodes 1 and 5 in $Y$ direction decrease, and the displacements of nodes 2 and 4 in $Y$ direction increase. Therefore, it can be concluded that the friction forces with disc, specific friction coefficient, and stick-slip motion caused the fluctuation of displacement in $Y$ direction.

4.4. Spatial Motion of Caliper. The caliper is connected to the guide pin through two rubber bushings, as shown in Figure 7(b). When creep groan occurs, the brake pressure is low and the deformation of the caliper is small; thus the displacements of the rubber bushing center can represent the spatial motion of caliper. Figure 22 shows the displacements of the rubber bushing centers. In Figure 22(a), the displacement of center 1 in $X$ direction is the same as that of center 2. The two centers move oppositely to $X$ direction and reach a static equilibrium position before $0.6 \mathrm{~s}$, and then the fluctuation of displacements occurs. In Figure 22(b), from $0.1 \mathrm{~s}$ to $0.6 \mathrm{~s}$, center 1 moves along $Y$ direction, but center 2 moves oppositely to $Y$ direction. After $0.6 \mathrm{~s}$, the displacements of the two centers fluctuate, and the directions of the fluctuation are opposite to each other. It can be seen that a torsional vibration occurs in the plane of $X Y$. Due to the action of brake pressure, the caliper moves in the opposite direction of $Z$ direction. Subject to the trend of the movement, the fluctuation of displacement in $Z$ direction can be attained, as shown in Figure 22(c), and the directions of the fluctuation are opposite to each other; thus it can be seen that a torsional vibration around $Y$ direction occurs. Therefore, the spatial motion of caliper is consistent with the spatial motion of inner lining, and it is caused by the friction forces of lining and the stick-slip motion of lining.

Based on the analysis of the displacements of lining and caliper, it can be seen that the characteristics of spatial motion of lining and caliper are complicated. Under the condition of low rotation speed and low brake pressure, the spatial motion of the lining and caliper can change the contact status between disc and lining and also the microcosmic friction coefficient. Therefore, it is possible to suppress brake creep groan by controlling the spatial motion of lining and caliper.

4.5. Vibration Characteristics of Caliper and Verification. In order to verify the model, the vibration characteristic of caliper is examined. Figure 23(a) shows the accelerations of caliper in each direction. From Figure 22, it can be seen that the caliper moves in each direction before $0.6 \mathrm{~s}$, but, from Figure 23(a), it can be seen that the caliper does not vibrate. This suggests that the analysis of the spatial motion of caliper before $0.6 \mathrm{~s}$ is reasonable in Section 4.4. After $0.6 \mathrm{~s}$, the caliper vibrates in all directions, which is a typical stick-slip vibration, and the magnitude of acceleration in $X$ direction is larger than the others, with the lowest in $Y$ direction. As much this characteristic is the same as that of the experimental results in Section 2.2.

After $0.6 \mathrm{~s}$, brake creep groan occurs, and the acceleration in $X$ direction includes several types of stick-slip vibration. Stage A is from $0.9 \mathrm{~s}$ to $1.6 \mathrm{~s}$ and stage B is from $1.8 \mathrm{~s}$ to $2.2 \mathrm{~s}$, and there are transition stages from $0.6 \mathrm{~s}$ to $0.9 \mathrm{~s}$ and from $1.6 \mathrm{~s}$ to $1.8 \mathrm{~s}$. The amplitude and period in stage A are larger than those in stage B. It can be seen that the characteristic is the same as that of the angular velocity of lining, as shown in Figure 13. Meanwhile, this characteristic of caliper acceleration change in different braking stage is consistent with experiment results.

Figure 24 shows the vibration characteristics in stage $\mathrm{A}$, in which the acceleration from $1.4 \mathrm{~s}$ to $1.5 \mathrm{~s}$ was chosen for analysis. In stage $\mathrm{A}$, the acceleration in $X$ direction is a periodic harmonic and contains two types of harmonics in each period. One has large amplitude with one-third period, and the other one has low amplitude with two-thirds period. Two limit cycles are shown in the phase diagram, which is consistent with the characteristic of two kinds of harmonic wave in time domain. Thus, these characteristics of caliper agree well with the experimental results of stage $\mathrm{D}$, as shown in Figure 4(c). From Figure 23(b), it can be found that the fundamental frequency in stage $\mathrm{A}$ is $34 \mathrm{~Hz}$, which is close to the fundamental frequency of $40 \mathrm{~Hz}$ measured in stage $\mathrm{D}$. 


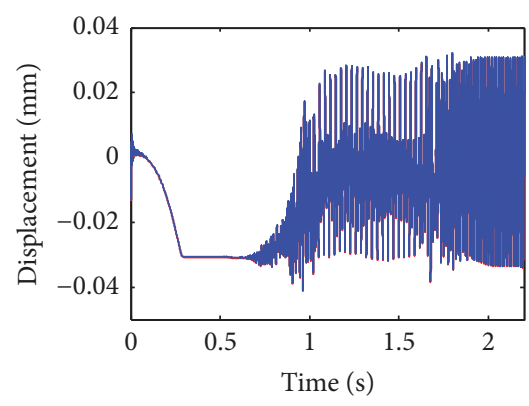

- (1)

- (2)

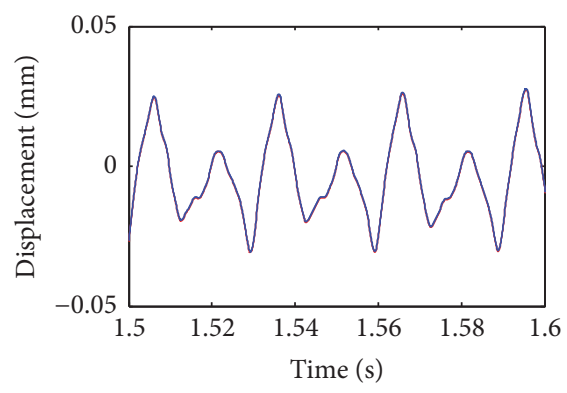

$-(1)$

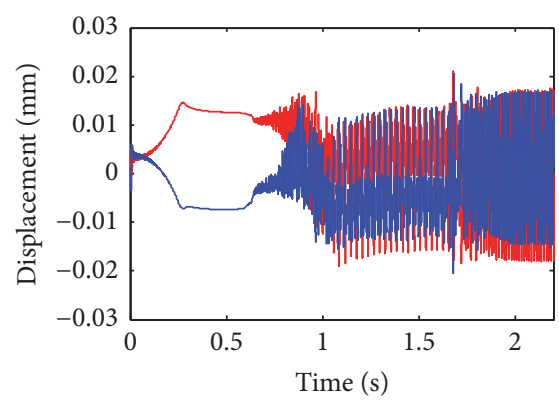

- (1)

- (2)

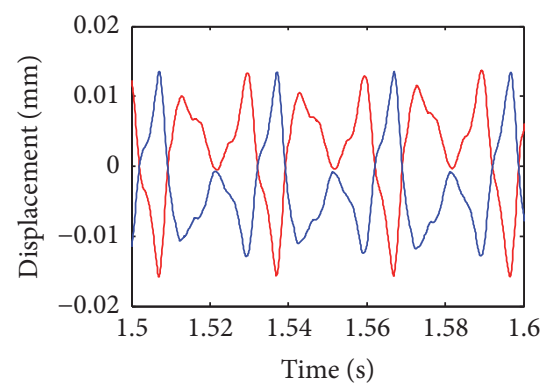

- (1)

- (2)

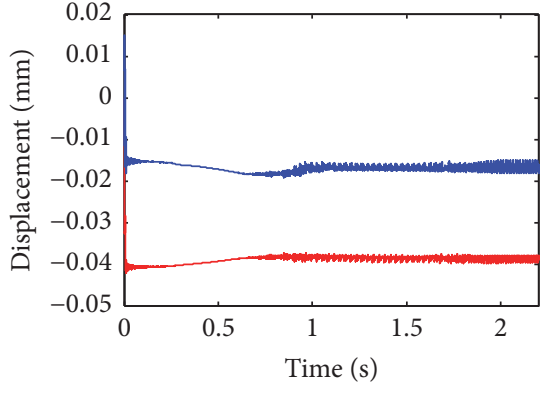

- (1)

$-(2)$

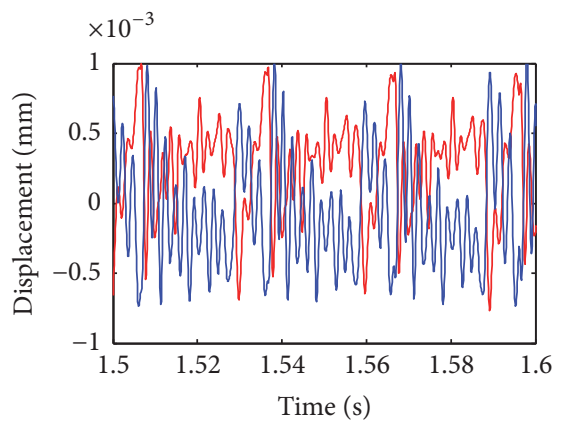

(1)

(a)

(b)

(c)

FIGURE 22: Displacements of the rubber bushing centers: (a) time history and partial curves in $X$ direction; (b) time history and partial curves in $Y$ direction; (c) time history and partial curves in $Z$ direction.

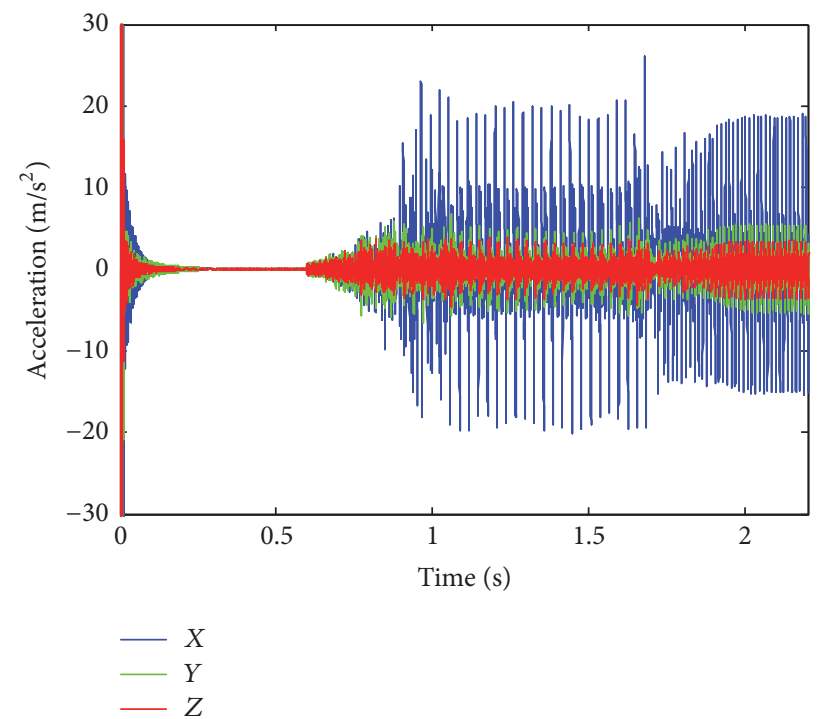

(a)

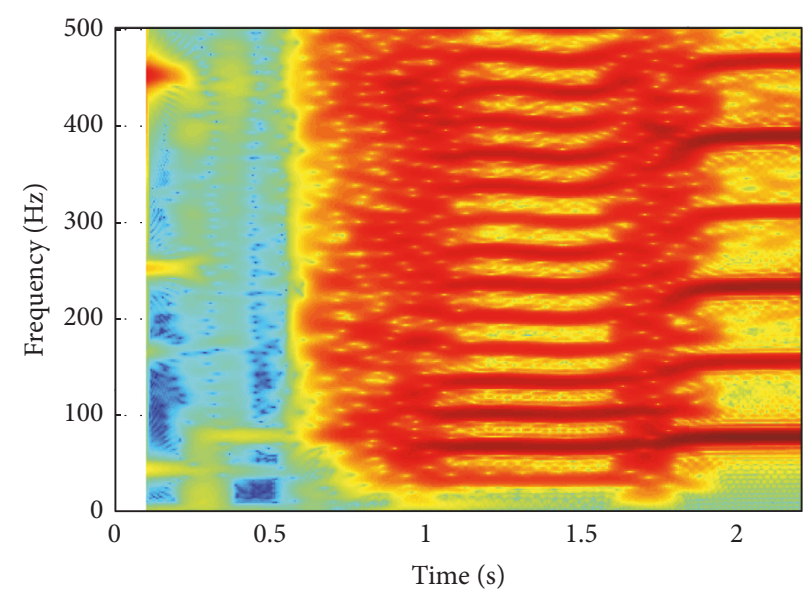

(b)

FIGURE 23: Vibration characteristics of caliper: (a) time history curves of acceleration in each direction; (b) time-frequency spectrum of acceleration in $X$ direction. 


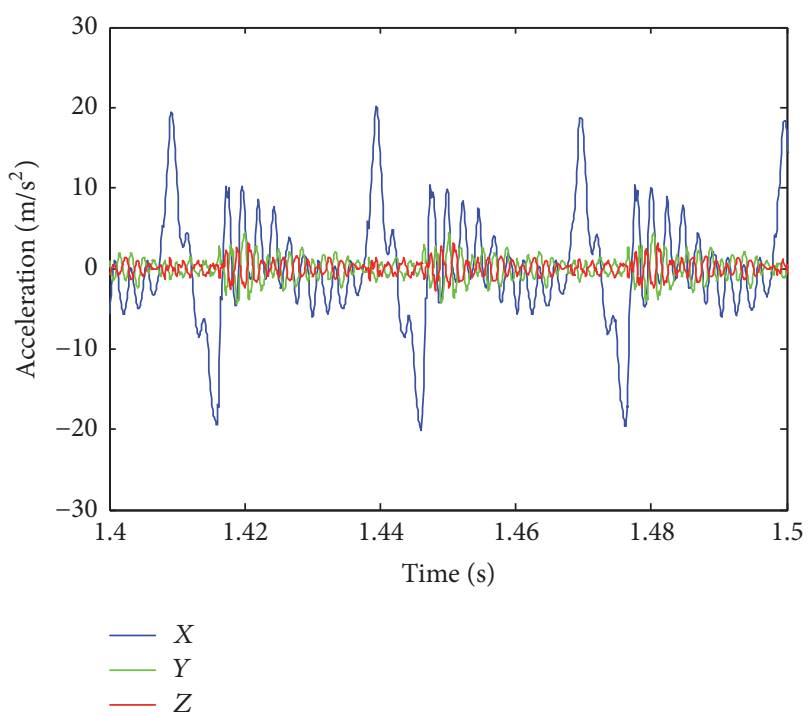

(a)

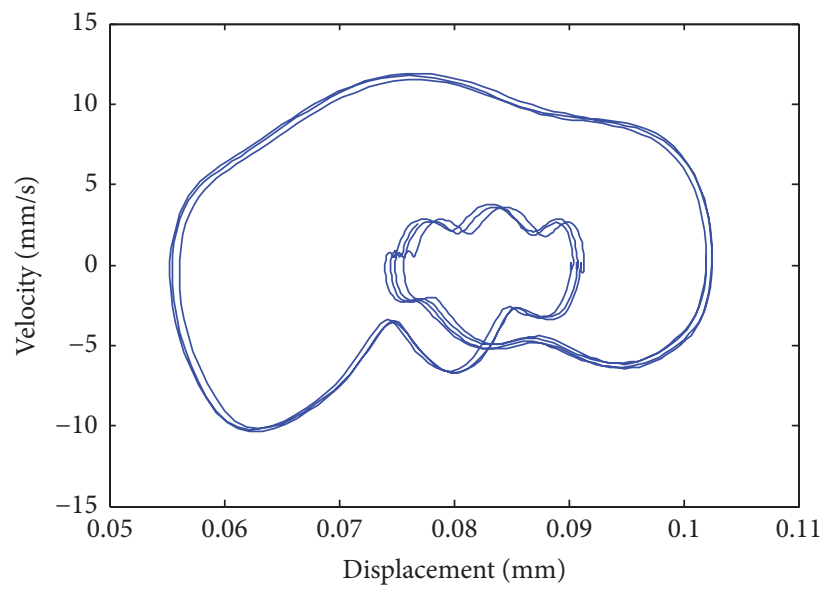

(b)

FIGURE 24: Vibration characteristics in stage A: (a) acceleration from $1.4 \mathrm{~s}$ to $1.5 \mathrm{~s}$; (b) phase diagram in $X$ direction.

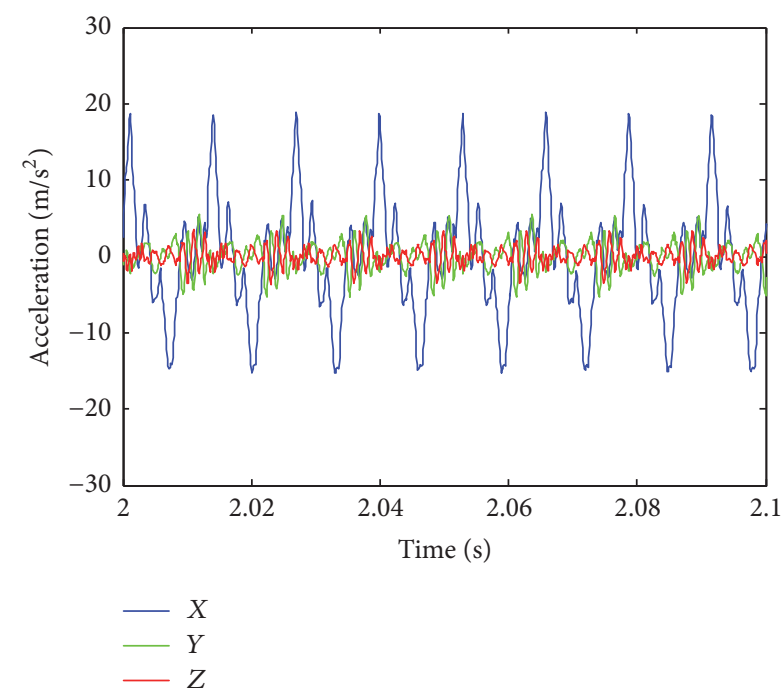

(a)

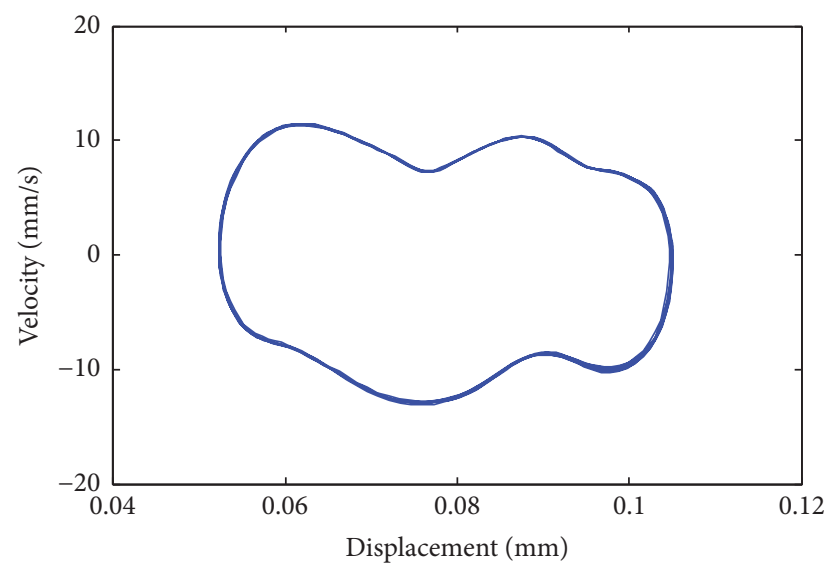

(b)

FIgURE 25: Vibration characteristics in stage B: (a) acceleration from $2 \mathrm{~s}$ to $2.1 \mathrm{~s}$; (b) phase diagram in $X$ direction.

Therefore, the simulation results in stage A agree well with the experimental results in stage $\mathrm{D}$.

Figure 25 shows the vibration characteristics in stage B, in which the acceleration from $2 \mathrm{~s}$ to $2.1 \mathrm{~s}$ was chosen for analysis. In stage $B$, the acceleration in $X$ direction is a single periodic and harmonic vibration, and a limit cycle is shown in the phase diagram. These characteristics of caliper agree well with the experimental results of stages A, C, and E, as shown in Figure 4(b). From Figure 23(b), it is exhibited that the fundamental frequency in stage $\mathrm{B}$ is $78 \mathrm{~Hz}$, and it is close to the fundamental frequency of $86 \mathrm{~Hz}$ measured in stages $\mathrm{B}$ and $\mathrm{F}$. Therefore, the simulation results in stage $\mathrm{B}$ agree well with the experimental results in stages $\mathrm{B}$ and $\mathrm{F}$.
Figure 26 shows the vibration characteristics in transition stage, in which the acceleration from $1.6 \mathrm{~s}$ to $1.8 \mathrm{~s}$ was chosen for analysis. In the stage, the acceleration in $X$ direction is changing from stage A to stage $\mathrm{B}$, and the acceleration in $X$ is unstable. Therefore, no obvious limit cycle exists in the phase diagram. These characteristics of caliper agree well with the experiment results of stages $\mathrm{A}, \mathrm{C}$, and $\mathrm{E}$, as shown in Figure 4(a). From Figure 23(b), it can be found that the frequency is close to that measured in stages $\mathrm{A}, \mathrm{C}$, and $\mathrm{E}$. Therefore, the simulation results in transition stages agree well with the experimental results in stages $\mathrm{A}, \mathrm{C}$, and $\mathrm{E}$.

There are still some differences between simulation and experimental results. For example, the magnitude of the 


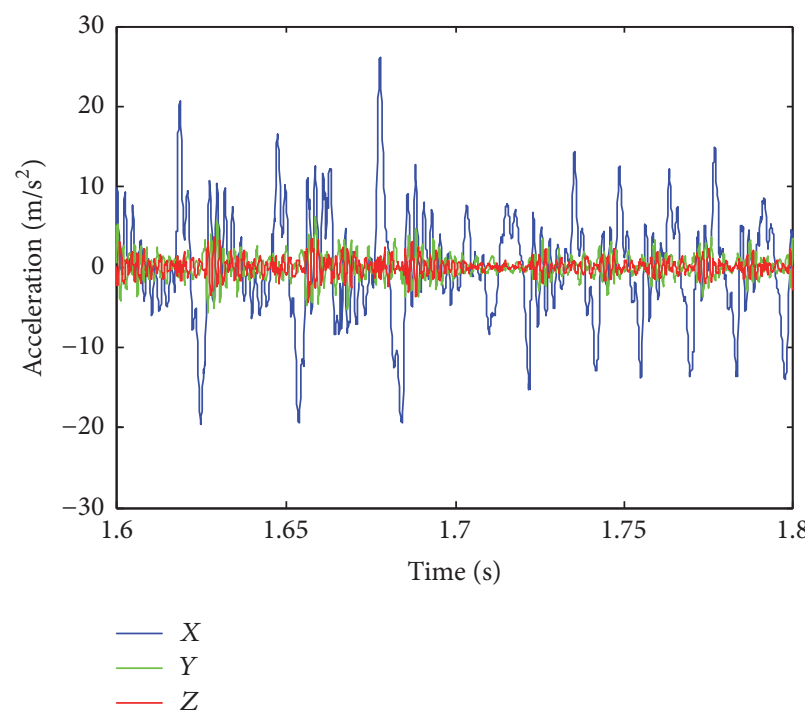

(a)

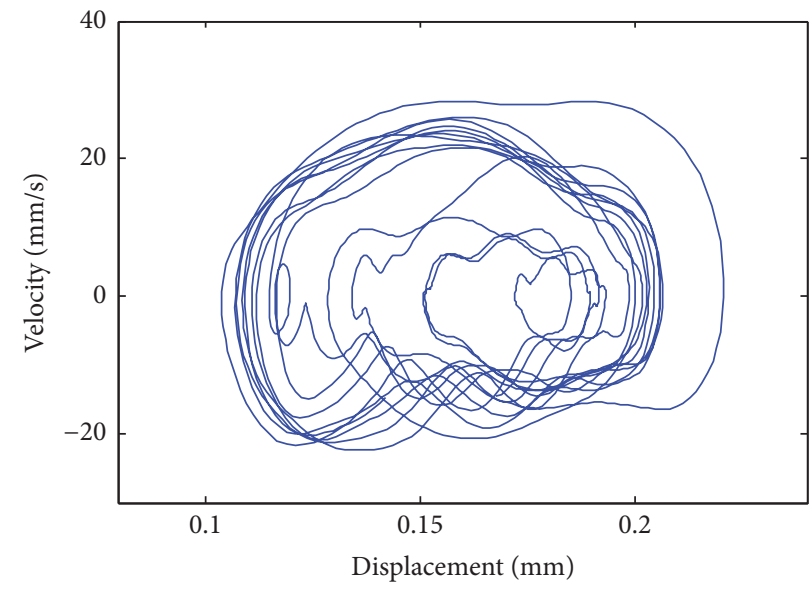

(b)

FIgURE 26: Vibration characteristics in transition stage: (a) acceleration from $1.6 \mathrm{~s}$ to $1.8 \mathrm{~s}$; (b) phase diagram in $X$ direction.

acceleration in simulation is higher than that in the experiment, which may be due to the difference of stiffness and damping in the suspension and tire and neglecting antinoise shim on pad. Although the difference of fundamental frequency is very small, the error is large in high-order frequency. This is because the difference may be magnified for many times in multifrequency components. The energy from $70 \mathrm{~Hz}$ to $90 \mathrm{~Hz}$ is large in both the simulation and experimental results. The complicated motions of pad in simulation are consistent with those in the experiment. The transient dynamic mode proposed in the paper is effective for the prediction and analysis of brake creep groan. Through the analysis of the natural frequency of the system, two modes are found to be related to the fundamental frequency. The first mode frequency is $29.4 \mathrm{~Hz}$ and it is the first torsional mode of disc. The second mode frequency is $82.4 \mathrm{~Hz}$ and it is the first twist mode of caliper. The two natural frequencies of the system are coincident with the fundamental frequencies of stages $\mathrm{A}$ and $\mathrm{B}$, respectively. Therefore, adjusting the frequency of the twist mode of caliper may be an effective way for brake creep groan control.

4.6. Effects of Subsystem Components. In order to study the effects of subsystems on brake creep groan, a benchmark FE model of brake corner is established, in which the subsystems including driveline, suspension, tire, and vehicle body are all neglected. The guide pins are fixed and the angular velocity is set at the axis of disc. The key parameters and simulation condition of the benchmark model are the same as those of the previous model considering the subsystems. The simulation results show that the benchmark model without subsystems can also reproduce the phenomena of stick-slip motion, the spatial motion, and the vibrations of linings and caliper. Taking the stick-slip motion as an example, as shown in Figures 27(a) and 27(b), it can be seen that the stick-slip motion from the benchmark model without subsystem is similar to the results of stage B from previous model with subsystems, shown in Figure 13. But the benchmark model cannot simulate the different type of stickslip motion in braking, which is an important characteristic of creep groan in the test. The frequency of the caliper acceleration in $X$ direction from benchmark model is shown in Figure 27(c). The fundamental frequency of the caliper acceleration is $96 \mathrm{~Hz}$, which is higher than the fundamental frequency of $86 \mathrm{~Hz}$ measured in experiment. Therefore, it can be concluded that the dynamic model with subsystems has higher accuracy than the model without subsystems.

\section{Conclusions}

Based on the experimental and theoretical analysis of brake creep groan, we can draw the following conclusions:

(1) A vehicle road test of creep groan is conducted under the condition of downhill. Complicated and different types of stick-slip motions are found and the characteristics of creep groan are changeable during braking. The acceleration of caliper in tangential direction has a high correlation with the interior noise and can be used for brake creep groan quantification. $40 \mathrm{~Hz}$ and its multifrequency and $86 \mathrm{~Hz}$ and its multifrequency are the dominant frequency components.

(2) A transient dynamic model including brake corner, driveline, suspension, tire, and vehicle body is established using finite element method for brake creep groan analysis. In the model, brake components are considered to be flexible body, and the subsystems including driveline, suspension, tire, and vehicle body are considered to be rigid body. Key parameters of the model, especially the friction coefficient, are defined. Based on the comparison between the simulation and experimental results of caliper vibration in time 


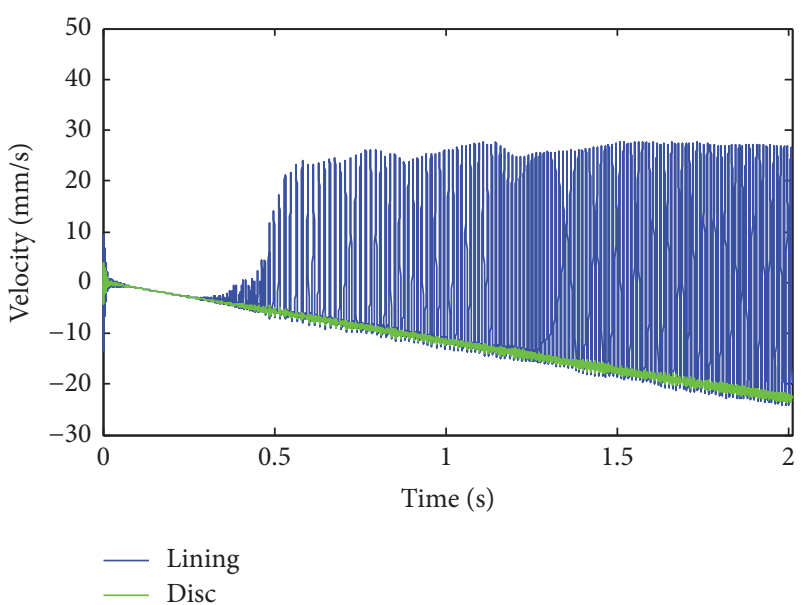

(a)

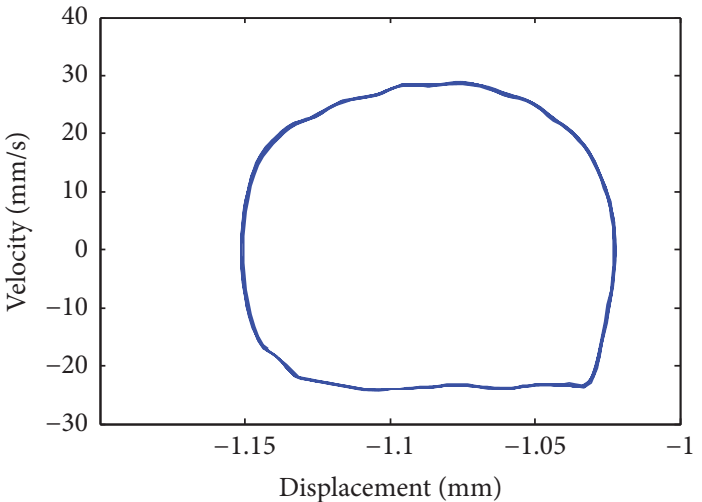

(b)

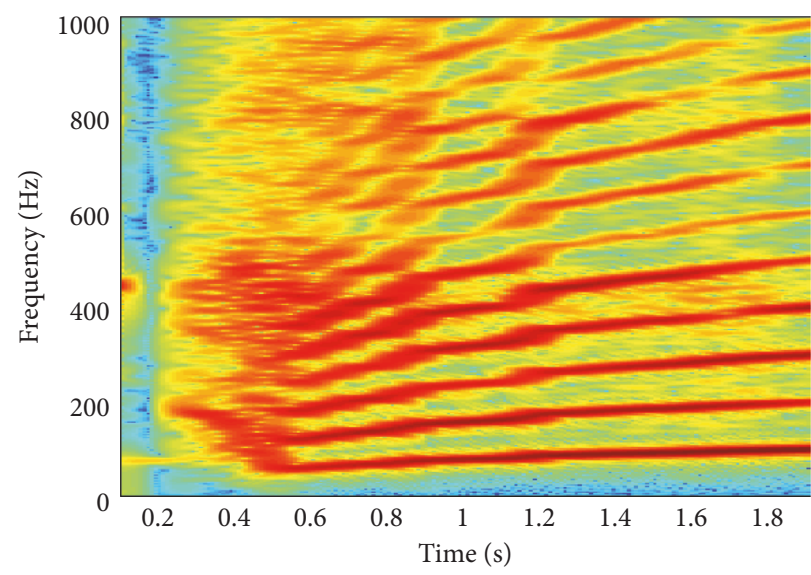

(c)

FIGURE 27: Simulation results of the benchmark model without subsystems: (a) stick-slip motion; (b) phase diagram of lining in tangential direction; (c) time-frequency spectrum of caliper acceleration in $X$ direction.

and frequency domains, it is found that the model is effective for the prediction and analysis of brake creep groan. It is also found that the model has higher accuracy than the model without considering the subsystems.

(3) Based on the model, the macroscopic and microscopic stick-slip motion and the spatial motion of lining and caliper are analyzed. In the early stage of braking, the lining and caliper have translational movements in tangential and radial directions and a torsional movement around axial direction. The macroscopic stick-slip motion occurs in each direction, and it relates to the microscopic sticking and slipping, friction coefficient, and forces as well as the contact status at the friction interface. It is noted that the microscopic and macroscopic friction coefficients of lining are different, which play critical roles in stick-slip motion.

(4) In NVH control, the control of the spatial motion of lining and caliper could be a solution for brake groan suppression, which will be presented in next paper.

\section{Conflicts of Interest}

The authors declare that there are no conflicts of interest regarding the publication of this paper.

\section{Acknowledgments}

This work was supported by the National Natural Science Foundation of China (Grants nos. 51575395 and U1564207) and Peak Discipline Opening Fund of Transportation Engineering of Tongji University (Grant no. 2016J012202).

\section{References}

[1] C. Cantoni, R. Cesarini, G. Mastinu, G. Rocca, and R. Sicigliano, "Brake comfort - A review," Vehicle System Dynamics, vol. 47, no. 8, pp. 901-947, 2009.

[2] L. Zhang, Y. Zheng, D. Meng, and P. Zhang, "Literature survey of friction induced automotive brake groan," Journal of Tongji University, vol. 44, no. 3, pp. 420-445, 2016.

[3] M. K. Abdelhamid, “Creep groan of disc brakes," SAE Technical Papers, 1995. 
[4] H. Jang, J. S. Lee, and J. W. Fash, "Compositional effects of the brake friction material on creep groan phenomena," Wear, vol. 250-251, no. 2, pp. 1477-1483, 2001.

[5] P. D. Neis, N. F. Ferreira, J. C. Poletto, L. T. Matozo, and D. Masotti, "Quantification of brake creep groan in vehicle tests and its relation with stick-slip obtained in laboratory tests," Journal of Sound and Vibration, 2015.

[6] H. Hetzler, D. Schwarzer, and W. Seemann, "Analytical investigation of steady-state stability and Hopf-bifurcations occurring in sliding friction oscillators with application to low-frequency disc brake noise," Communications in Nonlinear Science and Numerical Simulation, vol. 12, no. 1, pp. 83-99, 2007.

[7] H. Hetzler, D. Schwarzer, and W. Seemann, "Steady-state stability and bifurcations of friction oscillators due to velocitydependent friction characteristics," Proceedings of the Institution of Mechanical Engineers, Part K: Journal of Multi-body Dynamics, vol. 221, no. 3, pp. 401-413, 2007.

[8] Z. Fuadi, S. Maegawa, K. Nakano, and K. Adachi, "Map of lowfrequency stick-slip of a creep groan," Proceedings of the Institution of Mechanical Engineers, Part J: Journal of Engineering Tribology, vol. 224, no. 12, pp. 1235-1246, 2010.

[9] X. Li, J. Li, M. Li, and B. Wen, "Analysis of the effect of disc brake system parameters on brake chatter," Journal of Vibration, Measurement and Diagnosis, vol. 37, no. 1, pp. 102-107, 2017.

[10] M. Bettella, M. F. Harrison, and R. S. Sharp, "Investigation of automotive creep groan noise with a distributed-source excitation technique," Journal of Sound and Vibration, vol. 255, no. 3, pp. 531-547, 2002.

[11] J. Brecht and K. Schiffner, "Influence of friction law on brake creep-groan," SAE Technical Papers, 2001.

[12] Z. Fuadi, K. Adachi, H. Ikeda, H. Naito, and K. Kato, "Effect of contact stiffness on creep-groan occurrence on a simple caliperslider experimental model," Tribology Letters, vol. 33, no. 3, pp. 169-178, 2009.

[13] A. R. Crowther and R. Singh, "Analytical investigation of stickslip motions in coupled brake-driveline systems," Nonlinear Dynamics, vol. 50, no. 3, pp. 463-481, 2007.

[14] A. R. Crowther and R. Singh, "Identification and quantification of stick-slip induced brake groan events using experimental and analytical investigations," Noise Control Engineering Journal, vol. 56, no. 4, pp. 235-255, 2008.

[15] L. Zhang, P. Zhang, and D. Meng, "Tests and theoretical analysis of creep groan in vehicle disc brake," Automotive Engineering, vol. 38, no. 9, pp. 1132-1139, 2016.

[16] M. Donley and D. Riesland, "Brake groan simulation for a McPherson strut type suspension," SAE Technical Papers, 2003.

[17] K. Uchiyama and Y. Shishido, "Study of creep groan simulation by implicit dynamic analysis method of fea (part 3)," $S A E$ Technical Papers, vol. 2015, 2015. 


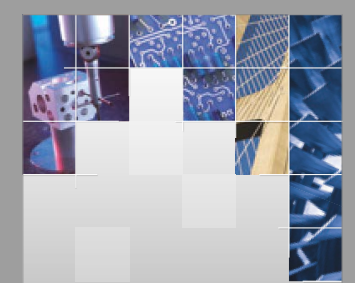

\section{Enfincering}
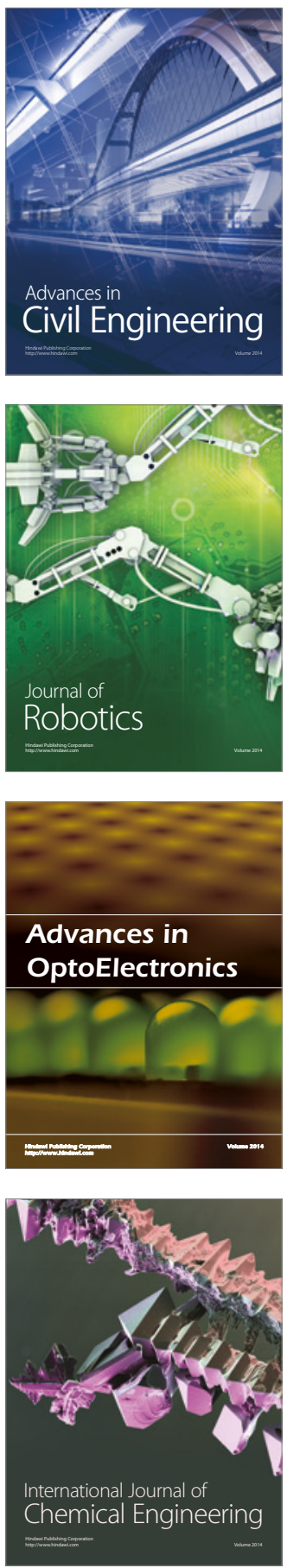

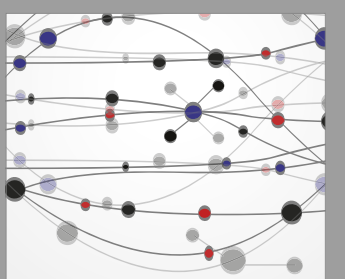

The Scientific World Journal

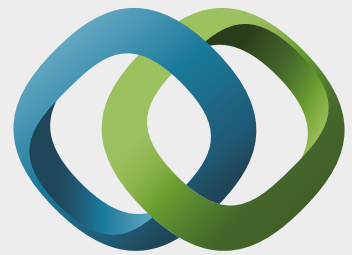

\section{Hindawi}

Submit your manuscripts at

https://www.hindawi.com
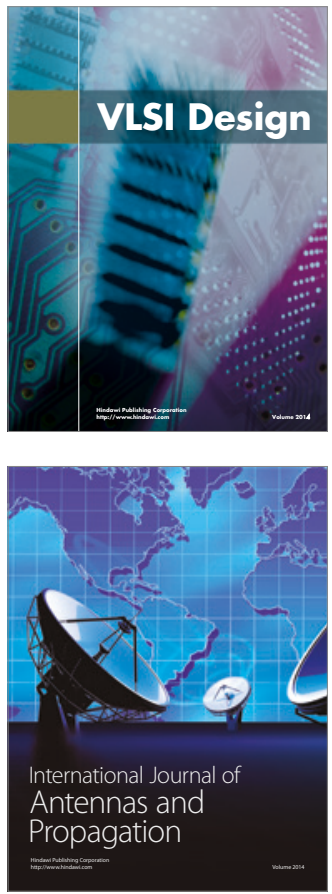

\section{Rotating}

Machinery
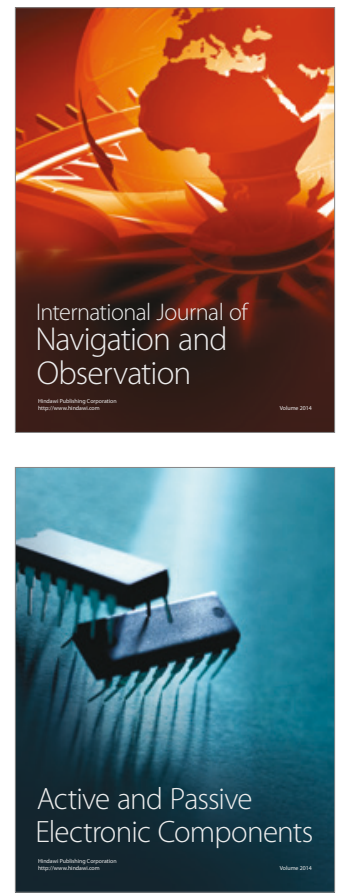
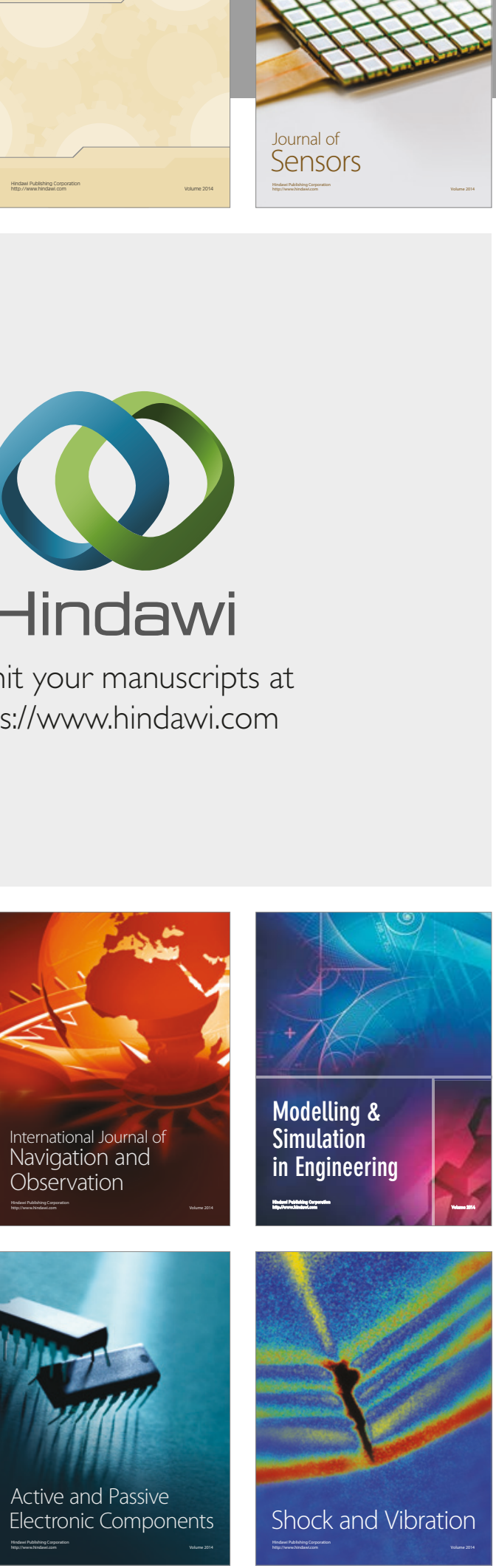
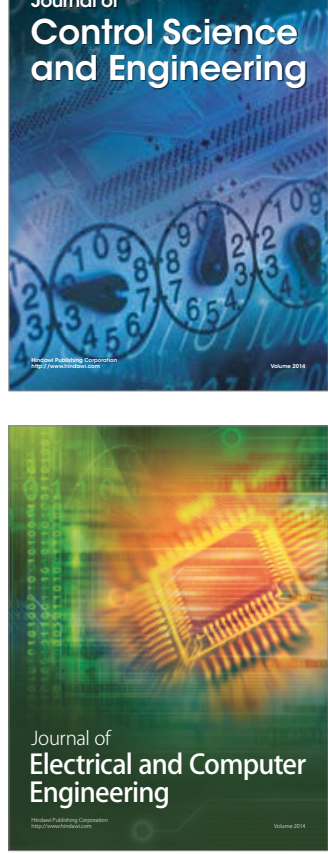

Distributed

Journal of

Control Science

and Engineering
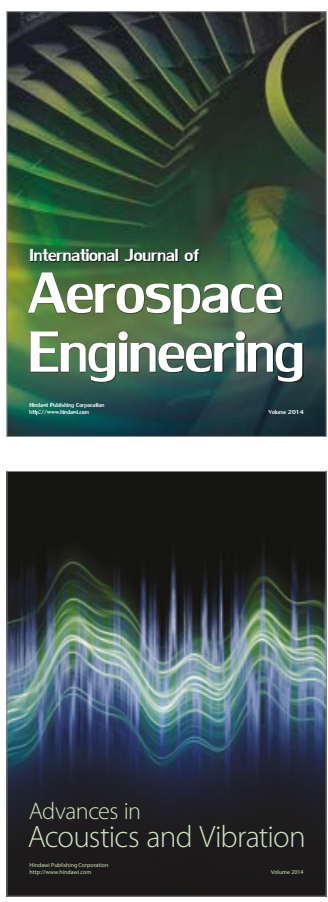

Sensor Networks 